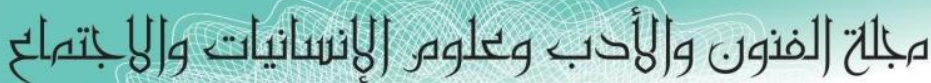

Journal of Arts, Literature, Humanities and Social Sciences

ISSN online: 2414 - 3383

ISSN print: 2616 - 3810

العدد (43) ايلول -سبتمبر 2019

¿ALHSS

Www.jalhss.com

\title{
أهمية النشاط الرياضي الترويحي في دمج الأطفال ذوي الإعاقة السمعية في السية \\ (دراسة ميدانية في معاهد المعاقين سمعياً)
}

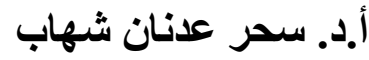

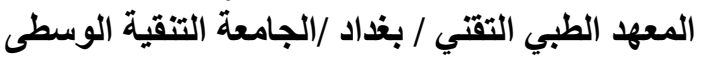
بغداد ـ - العراق

\author{
أم.د. حيدر ماجد الهاشمي

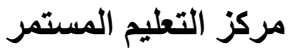 \\ بغذاد ـ العراق
}

الملخص

تعد رياضة الأشخاص ذوب الإعاقة من الرياضات الترويحية ذات الأهمية الكبرى في إعادة وتأهيل المعاقين سمعياً

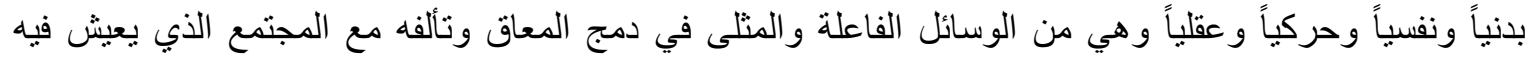

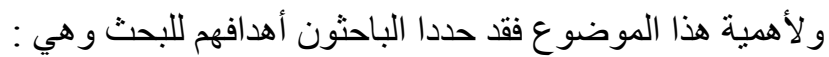
1- نتعرف على معنى الأنشطة الرياضية الترويحية.

2- نتعرف عن معنى الإعاقة السمعية.

3- التعرف على الصعوبات التي تو اجه المعاقين سمعياً عند ممارسة الأنشطة الرياضية.

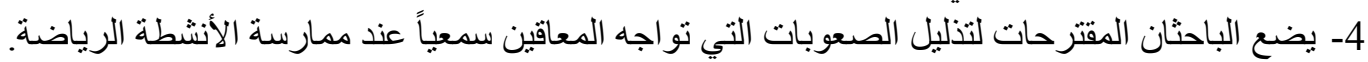

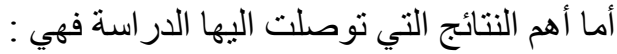
1- أن ممارسة الأنشطة الرياضية تهرف إلى الثئية التنمية الثاملة للفرد المعاق سمعياً نفسياً وعقلياً واجتماعياً بوزن نسبي

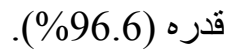

2- عدم تو افر المستلزمات و التجهيزات و القاعات الرياضي بوزن نسبي قدره (75.3\%).

3- لا يوجد معلم مختص بتدريب الطلبة للممارسة الأنشطة الرياضة الترويحية وزن نسبي قدره (74.6\%).

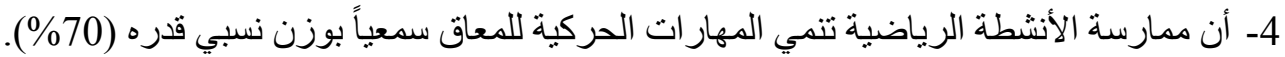

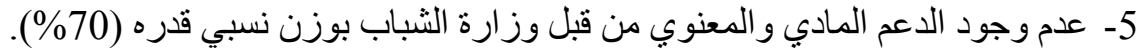

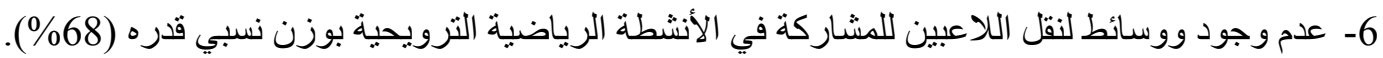

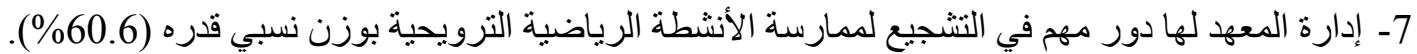
8- هل تمارسة النشاط و الرياضي في وقعت محدد بوزن نسبي قدره (54\%). 


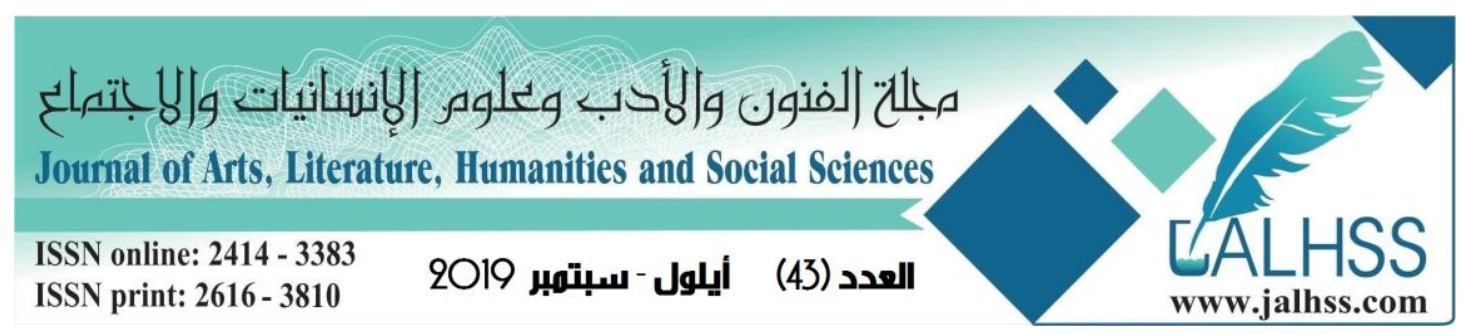

\title{
The Importance of Recreational Sports Activity in the Integration of Children with Hearing Disabilities (Field Study in Hearing Impaired Institutes)
}

\author{
Prof. Assist. Dr.Haider Majid Al- \\ Hashami \\ Continuing Teaching Centre \\ Baghdad - Iraq
}

\author{
Prof. Sahar Adnan Shihab \\ Technical Medical Institute / Baghdad / Middle \\ Technical University \\ Baghdad - Iraq
}

\begin{abstract}
The sport of individuals with disabilities is one of the recreational sports of great importance in the rehabilitation of the physically, psychologically, physically and mentally disabled. It is one of the most effective and ideal means in integrating the disabled and their familiarization with the society in which we live. Because of the importance of this topic, the researchers identified their research objectives and those are: 1- Acting on the basis of recreational sports activities.

2- Acting on the basis of hearing impairment.

3- Identify the difficulties faced by the hearing impaired through sports activities.

4- Researchers are developing proposals to overcome the difficulties faced by hearing impaired people in sports.

5- Researchers develop proposals to overcome the difficulties faced by people with hearing disabilities when exercising.

The most important findings of the study are:

1- The exercise of sports activities aims at the comprehensive development of the person with hearing, mental, psychological and social disabilities with a relative percentage of $(96.6 \%)$.

2- Lack of supplies, equipment and sports halls with a relative percentage of $(75.3 \%)$

3 - There is no teacher specialized in training students to practice recreational sports with a relative percentage of $(74.6 \%)$

4- The exercise of sports activities develops motor skills for the hearing disabled people with a relative percentage of $(70 \%)$.

5- Lack of financial and moral support from the Ministry of Youth with a relative percentage of $(70 \%)$

6- Lack of means to transport players to participate in recreational sports activities with a relative percentage of $(68 \%)$.

7- The management of the institute has an important role in encouraging the exercise of recreational sports activities with a relative percentage of $(60.6 \%)$.

8- Exercise at a specific time with a relative percentage of $(54 \%)$
\end{abstract}




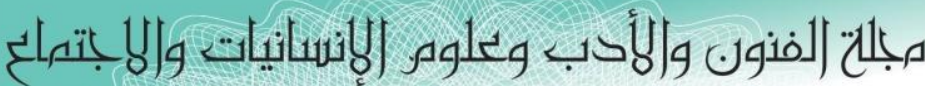

Journal of Arts, Literature, Humanities and Social Sciences

ISSN online: 2414 - 3383

ISSN print: 2616 - 3810

\section{العدد (43) ايلول - سبتمبر 2019}

أن ممارسة الأنشطة الرياضية الترويحية لها دور أساس في حياة المعاقين سمعياً وذلك لأنها خير وسيلة للمحافظة على

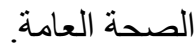
إذ يرى جون وديوي أن النشاط الرياضي يعد نشاطاً هادفاً وبناءً؛ إذ يساهم في تتمية المهارات واتونة القيم و الاتجاهات

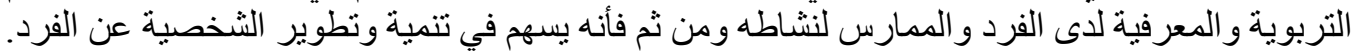

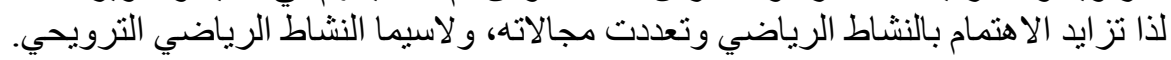

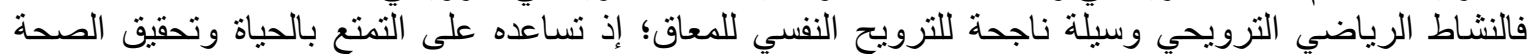

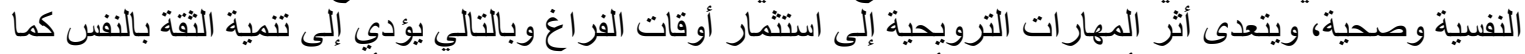

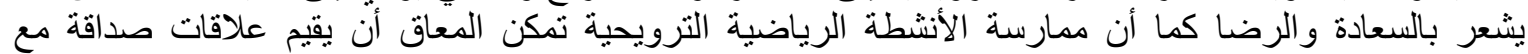

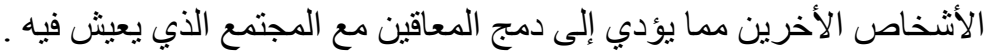

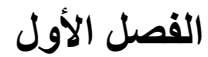 \\ الإطار النظري للبحث الأف}

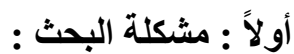

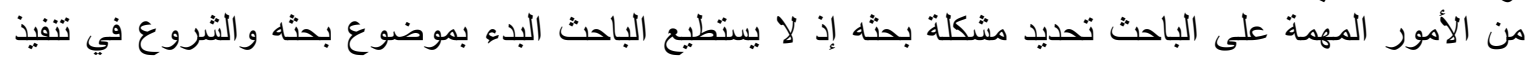
مر احلة العلمية من دون ثبات تحديد عنو ان بحثه أو اختيار مشكلة البحث الذئ الذي ينوي در استها وتحليلها مع فهم جو انبها

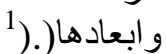
في بحثنا الحالي تم تحديد المشكلات التي تواجه ممارسة الأنشطة الرياضية الترويحية للمعاقين سمعياً منها عدم تو افر سأحات رياضية مهيئة إقامة الأنشطة الرياضية الرية. علاوة على ذللك عدم تو افر المستلزمات التئة الرياضية كالكرات باتية باختلاف أنو اعها واحجامها و الملابس و التغذية الصحية

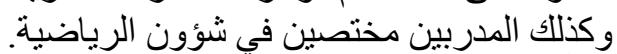

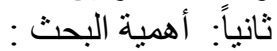
أن ممارسةّة الأنشطة الريّة الرياضية الترويحية للمعاقين سمعياً لها جو انب متعددة منها الترويح النفسي للمعاقين واسترجاع

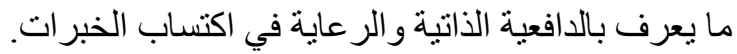

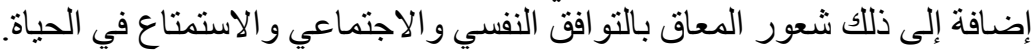

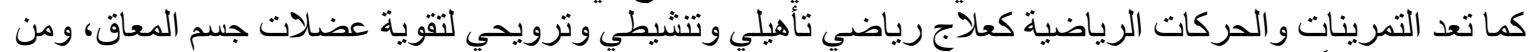

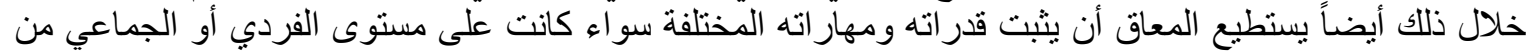

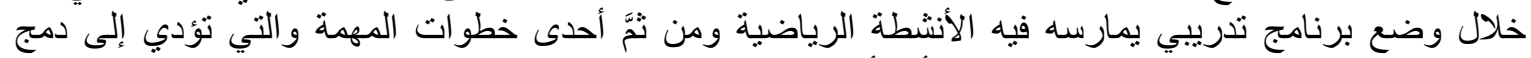

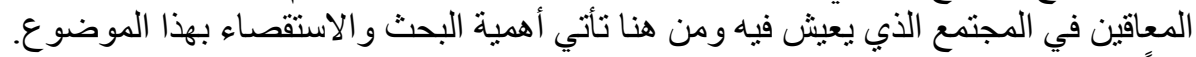

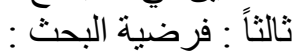
هناك فروق للأهمية للعو امل التي تحول دون مدارسة الأنشطة الرياضية الترويحية.

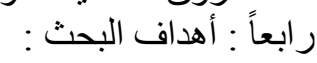

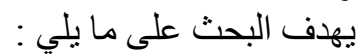
1- تعرف على معنى الأنشطة الرياضية الترويحية. 2- 2- تتعرف على معنى الإعاقة السمعية.

3- تتعرف على الصعوبات التي نو اجه المعاقين سمعياً عند ممارسة الأنشطة الرياضية الترويحية.

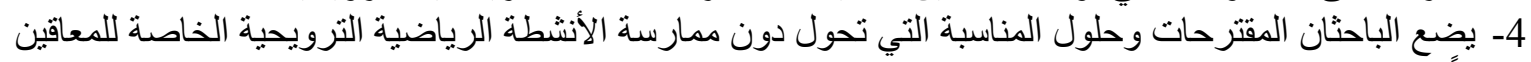

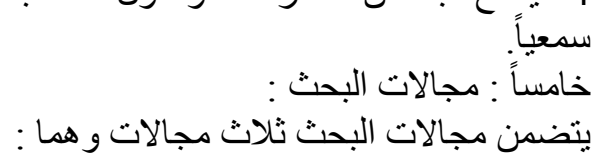

1) د. احسان محمد الحسن، مناهج البحث الاجتماعي، دار و ائل للنشر، ط1، الأردن، 2005، ص183. 


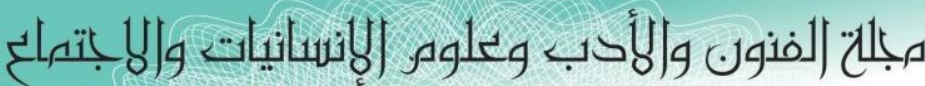

Journal of Arts, Literature, Humanities and Social Sciences

ISSN online: 2414 - 3383

ISSN print: 2616 - 3810

\section{أيلول - سبتمبر 2019}

العدد (43)

1- المجال المكاني : ويقصد به المكان الذي اجريت فيه الدراسة إذ تم تحديد مكان البحث معهد الأمل للصم واليكم

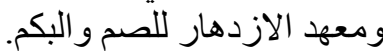

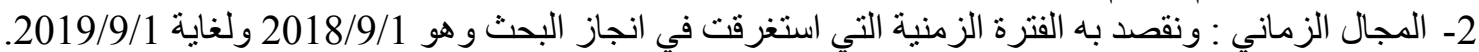

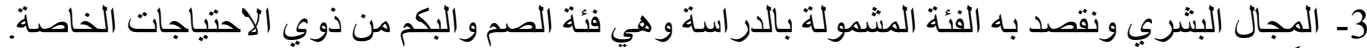

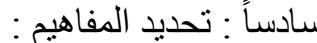
من الأمور المهمة التي يجب أن تأخذ بنظر الاعتبار هي تعريف المفاهيم والمصطلحات التي وردت في البحث ومن أهم مصطلحات التي وردت فهي كالآتي:

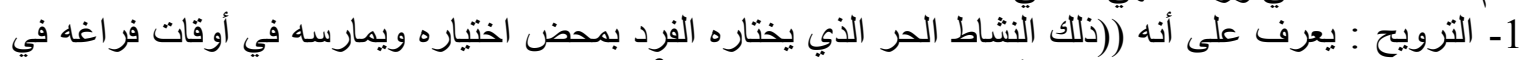

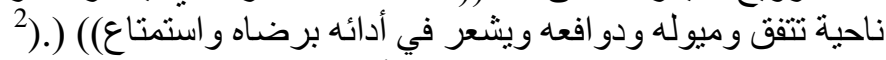

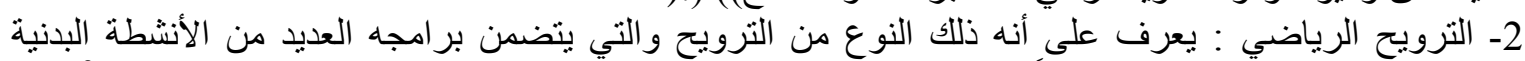

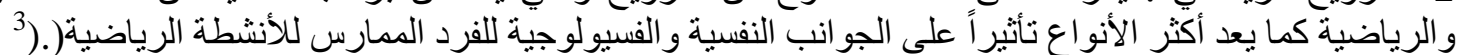

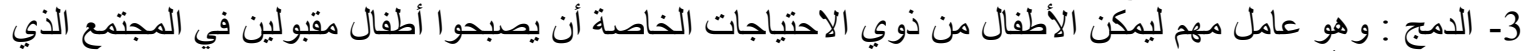

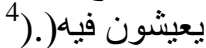

4- الدمج الاجتماعي : وتعني بها عملية دمج الفرد في نظام التبادلات الخاص بالجماعة الاجتماعية التي ينمو فيها(.).

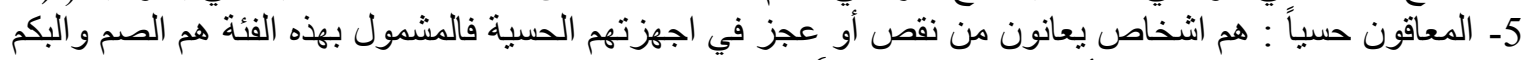

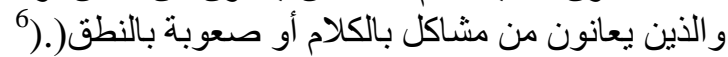

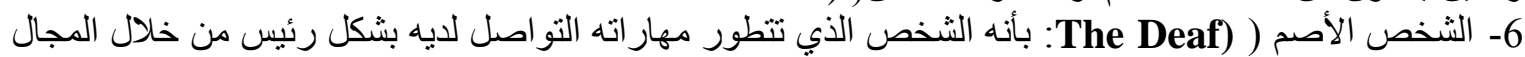

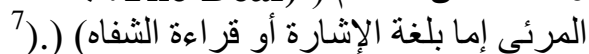
وتعرف أيضاً فقدان القدرة على السمع لذلك فهو غبر قادر على اكتساب اللغة وفهها وكذلك عدم القدرة على الكلام

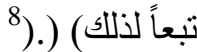
أما تعريف ضن ضعاف السمع (فيقصد به المعاق الذب يشكو من ضعف في السمع ولكنه يستجيب اللغة ويفهمها وكذلك عدم

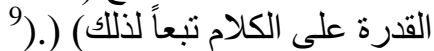

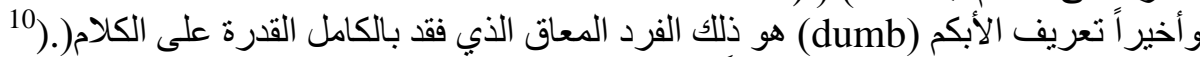

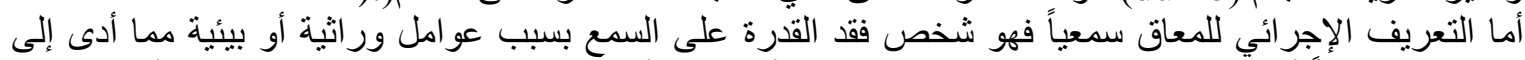

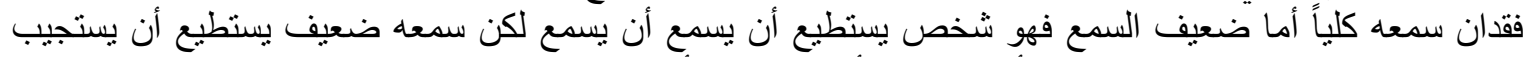

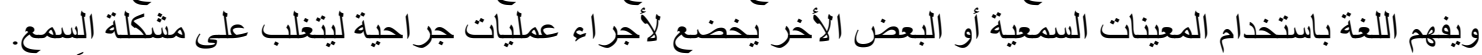

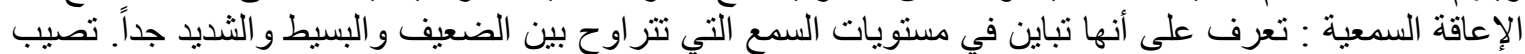

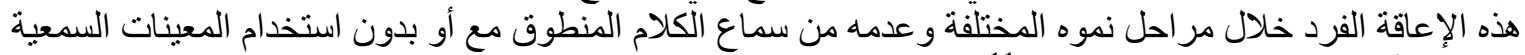

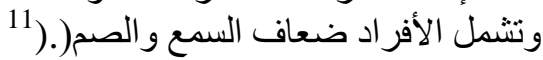

2) د. عبد الحافظ محمد سلامة، تصميم الوسائل التعليمية و انتاجها لذوي الاحتياجات الخاصة، الأردن، اليازوري،

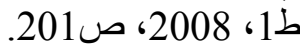
3) محمد الحمامي، عايدة عبد العزيز، الترويح بين النظرية والتطبيق، القاهرة، مركز الكتاب والنشر، ط2، 1998، ص ص49. n 4) أ.م.د. سحر عدنان شهاب، وجهات نظر معلمي التربية الخاصة حول عملية دمج المعاقين في المجتمع، بحث

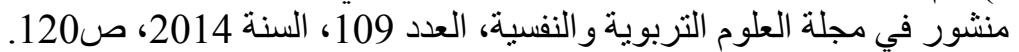

5 () Erikson, (e) adolescence et - equate - disentitle Flammarion - Paris, 1972, P.100. 6) د. عبد السلام نعمة الأسدي، الرعاية الاجتماعية لذوي الاحتباجات الخاصة (المعاقون)، بغداد ، هيئة التعليم التقني،

$$
\begin{aligned}
& \text { 2008، ص. ص. } \\
& \text { 7) أ.م.د. حسن هادي الهلالي، رياضة المعاقين، بغداد، مكتبة الفقمة، 2014، ص78. } \\
& \text { 8) المصدر نفسه. } \\
& \text { 9) المصدر نفسه . } \\
& \text { 10 المصدر نفسه. }
\end{aligned}
$$




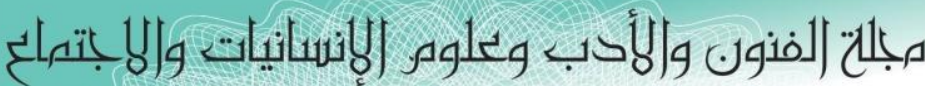

Journal of Arts, Literature, Humanities and Social Sciences

ISSN online: 2414 - 3383

ISSN print: 2616 - 3810

أيلول - سبتمبر 2019

العدد (43)

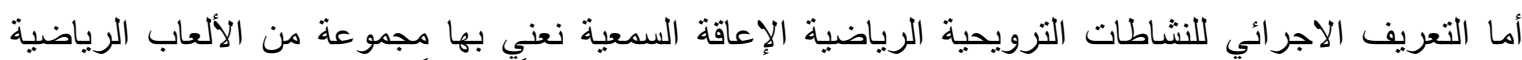

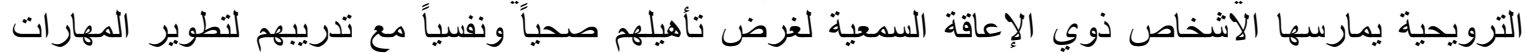
و القابليات لديهم لكي يشغل أوقات فر اغهم وبالتالي دمجهم مع المجنمع الذي ليعيشون فيه.

\section{الفصل الثاني \\ أهمية الترويح - النظريات التي تفسر الترويح}

يتضمن هذا الفصل محورين وسوف نتناول كل محور بشيء من التقصيل:

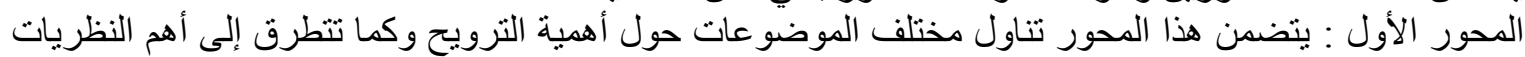

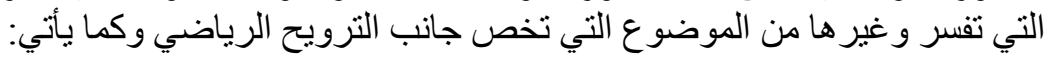

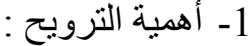
تشير الجمعية الأمريكية للصحة والتربية التربية البدنية والترويح إلى إسهامات الترويح في حياة المجتمعات المعاصرة في النقاط الآتية : 1- 1 - توفير حياة شخصية و عائلية تتم بالسعادة و الاستقرار.

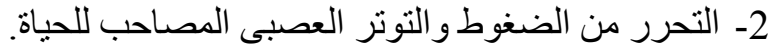

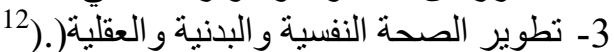

4- تحقيق الحاجات الإنسانية للتعبير عن الذاتية النات.

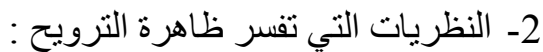

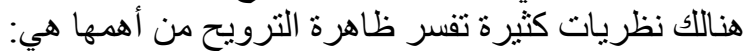

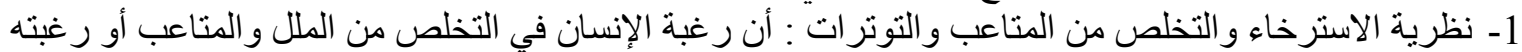

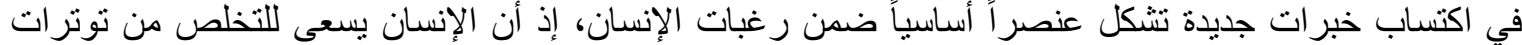

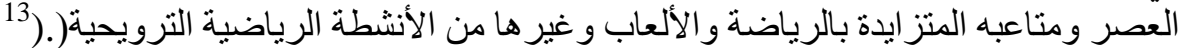

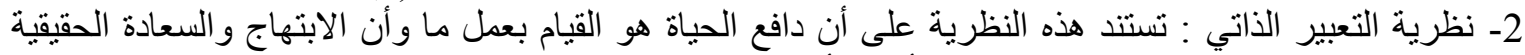

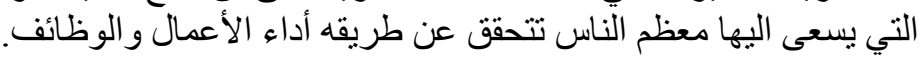

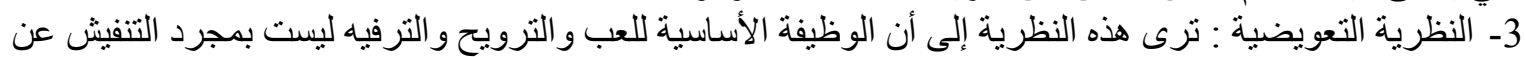

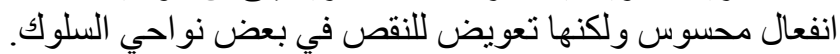
4- النظرية التبادلية : نرى هذه النظرية أن الإنسان عندما يقوم بوسيلة ترويحية معينة يجد فيها تحقيقات التيا لاتشباع حاجاته

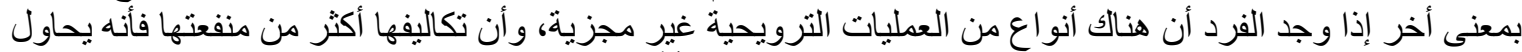

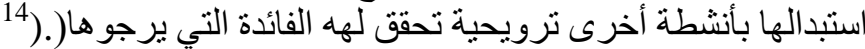

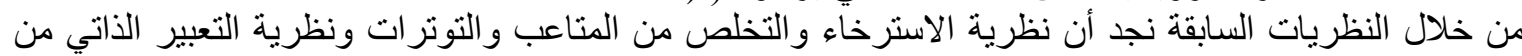

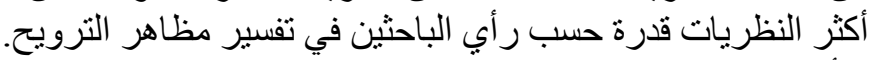
التأثير ات الإيجابية للترويح ونتشمل :

صن 11 طه سبد علي أبو الليل، التربية البدنية والرياضية لذوي الاحتباجات الخاصة، بيروت، مكتبة الفلاح، ط1، 2005، ص50.5

${ }^{12}$ ) Tonis. Shippen Berg, Georgef, Koob- "Recent Apvances in animal Models of Drug Addiction $>$.

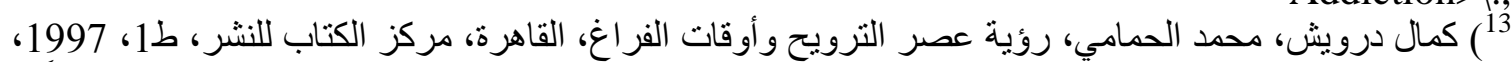

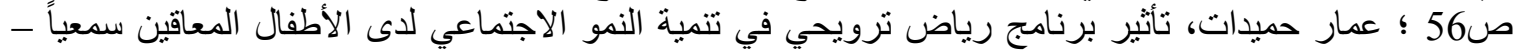

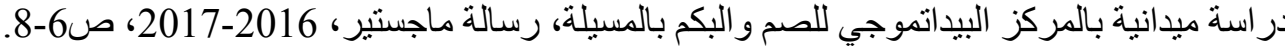

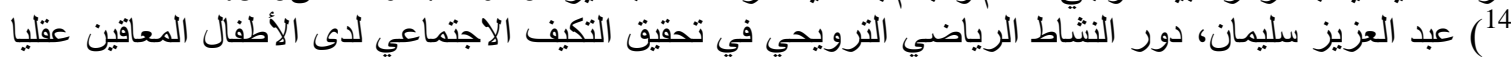

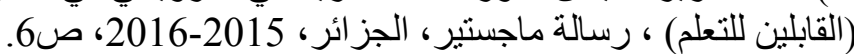




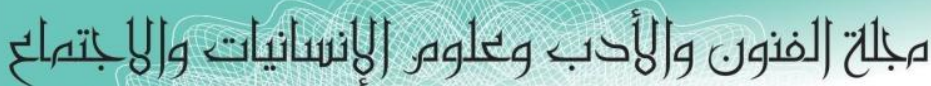

Journal of Arts, Literature, Humanities and Social Sciences

ISSN online: 2414 - 3383

ISSN print: 2616 - 3810

العدد (43) ايلول - سبتهبر 2019

1- الصحة و اللياقة البدنية وكفاءة و الاجهزة الحيوية.

2- البهجة والسعادة و الاستقر ار الانفعالي.

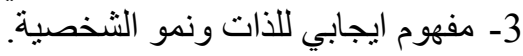

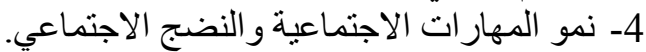

5- التوجيه الاجتماعي للحياة و القيم.

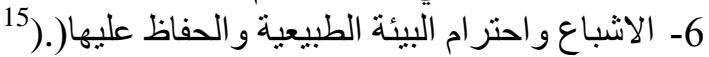

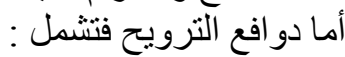

1- مكونات ودو افع اكتساب الصحة و اللياقة البدنية.

2- مكونات ودو افع الميول الرياضية.

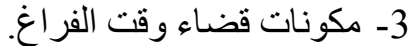

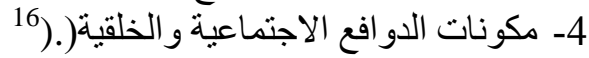

5- مكونات ودو افع النواحي العقلية و النفسية.

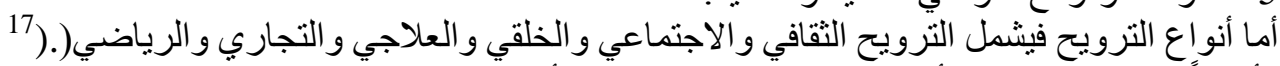

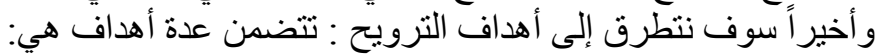

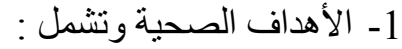
1- 1- نطوير الصحة الفردية للفرد. 2- 1- تنمية العادات الصحية المرغوبة الصنة.

3- الوقاية من التعرض للألأصابة.

4- الحد من الآثار السلبية للعو امل النفسية.

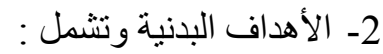

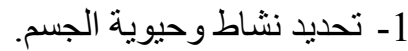
2- 2- المحافظة على الحالة البدنية. 3- - الاحتفاظ بالقو ام و الرشاقة.

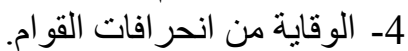

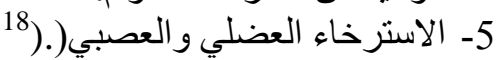
3- الأهداف المهارية وهي التي تتعلق بتعليم وتتمية المهار ات الحركية بصورة عامة وتتشل :

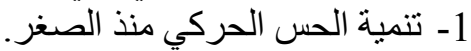
2- تعليم المهار ات الحركية للألعاب و الرياضات الحئ المختلفة منذ الصغر. 3- الارتقاء بمستوى أداء المو هوبين لئن رياضياً.

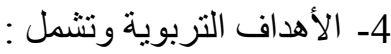

1- 1- تنمية وتثكيل الثخصية المتكاملة للفرد.

2- تزويد الفرد بالعديد من الخبر اتئ.

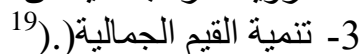
5- الأهداف النفسية وتشمل :

15) د. عبد الحافظ سلامة، تصميم الوسائل التعليمية وانتاجها لذوي الاحتياجات الخاصة، مصدر سابق، ص202.204

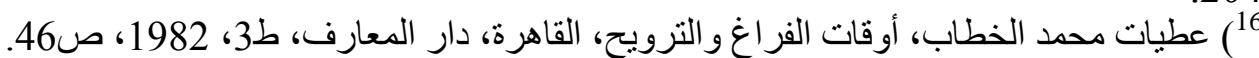

${ }^{17}$ () Malcolm. D.. a module. Fundamental of scientific method in Psychology. W. c.

Brown 20 med. Dubuque 1972, P.

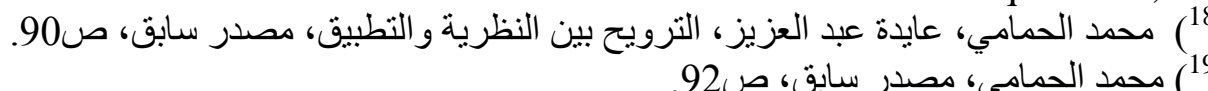




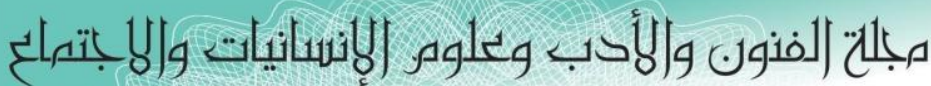

Journal of Arts, Literature, Humanities and Social Sciences

ISSN online: 2414 - 3383

ISSN print: 2616 - 3810

\section{العدد (43) ايلول - سبتهبر 2019}

$$
\begin{aligned}
& \text { 1- تنمية الرغبة و استثارة الدافعية نحو ممارسة النشاط الحركي . } \\
& \text { 2- اشباع المبل للنشاط. } \\
& \text { 3- تحقيق الاسترخاء و التوازن النفسي. } \\
& \text { 4- الحد من التوتر( }
\end{aligned}
$$

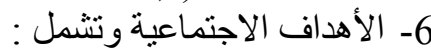

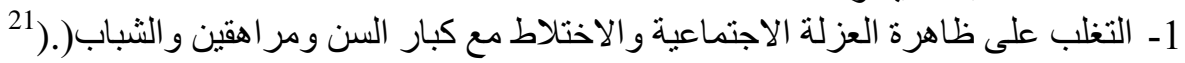

$$
\begin{aligned}
& \text { 2- تشكيل السلوك الاجتماعي السوي. } \\
& \text { 3- تنمية مهار ات التو اصل. } \\
& \text { 7- أهداف ثقافية وتشمل : 1ـ } \\
& \text { 1- تزويد الفرد بالثقافة الرياضية. } \\
& \text { 2- تشكيل اتجاهات ايجابية. }
\end{aligned}
$$

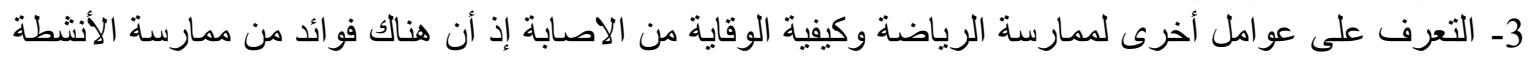

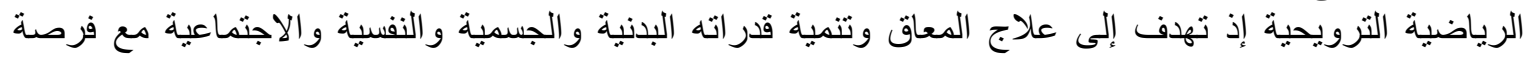

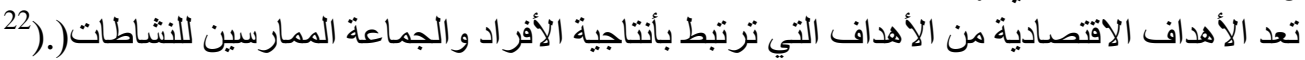

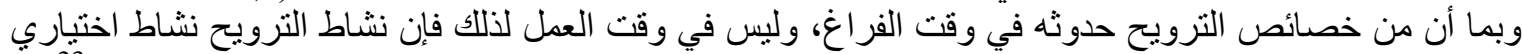

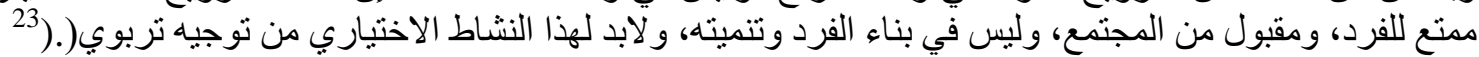

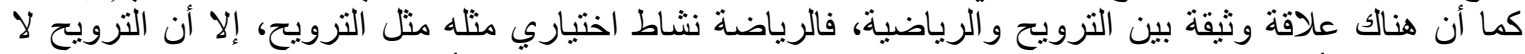

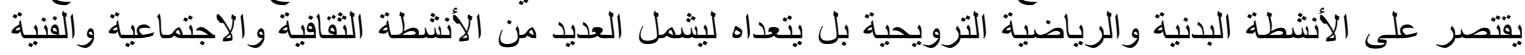

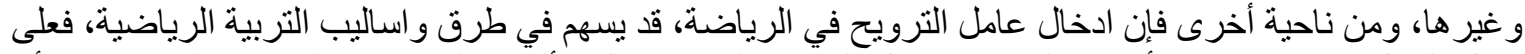

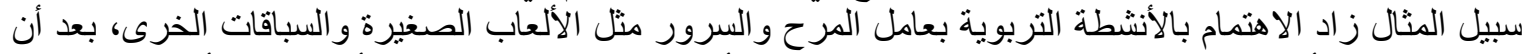

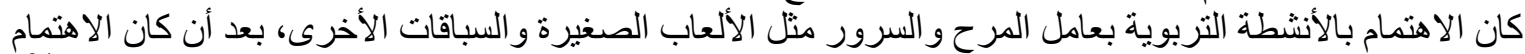

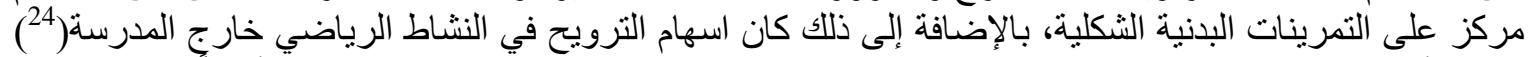

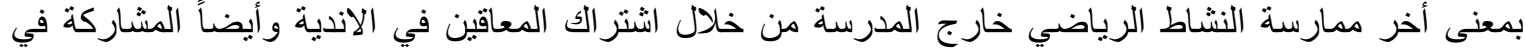

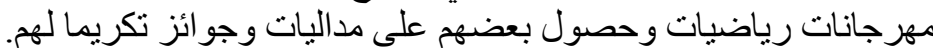

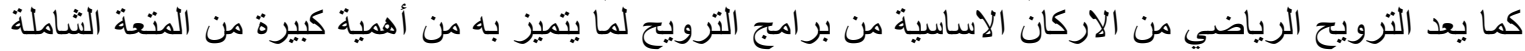

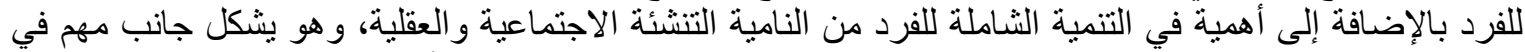

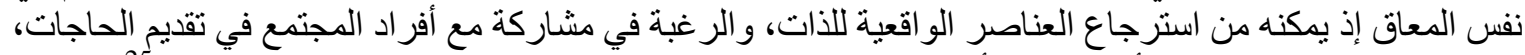

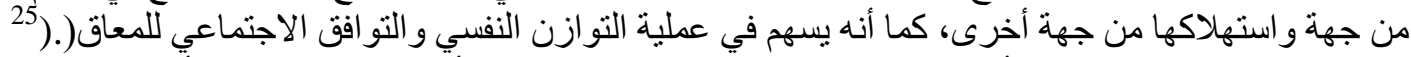

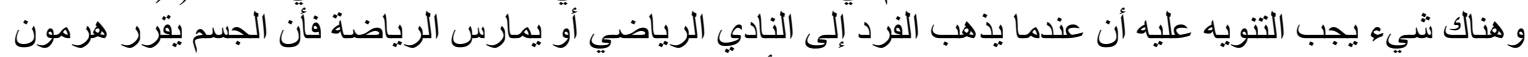
endor Phin نحتاج على الأول (30) دقيقة وما ليحصل على اليومية من الاندروفين وثنم من خلال مشاهدة أثنياء مضحكة أو بأو ممارسة الرياضة.

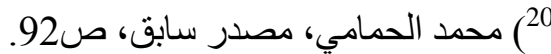
21 غوزيل سابيرونا اليكس زنبوفيف، اليف، النوادي الرياضية المحلية الحضرية و الأطفال المهاجرين و الثباب في روسيا،

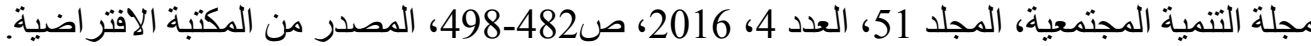

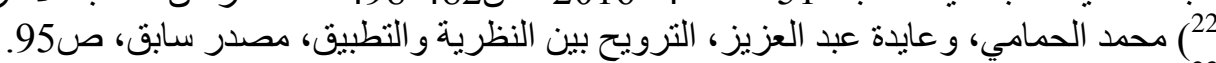

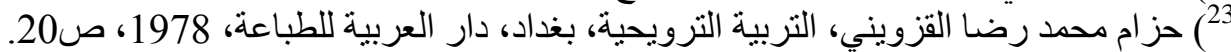

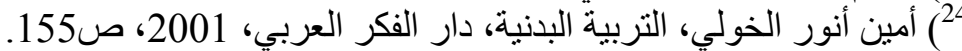
25) مروان عبد المجيد إبر اهيم، الألعاب الرياضية للمعوانية الفين، دار الفكر لطباعة والنشر، ط1، 1999، ص111.
} 


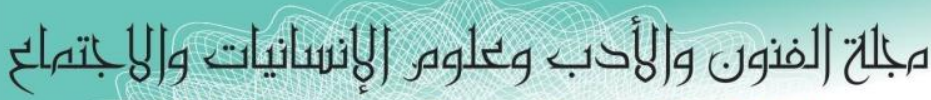

Journal of Arts, Literature, Humanities and Social Sciences

ISSN online: 2414 - 3383

ISSN print: 2616 - 3810

\section{العدد (43) ايلول - سبتهبر 2019}

\section{الفصل الثالث \\ الجهاز السمعي واسباب ضعف السمع والأنشطة الرياضية للصم والبكم}

يتناول الفصل الثالث ثلاث محاور وهي : الإول

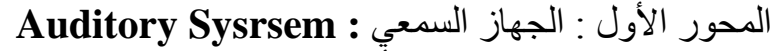

ينكون الجهاز السمعي من الآذن الخارجية والوسطى والخارجية وفيما يلي شرح مختصر على كل جزء من ازاء الجهاز السمعي.

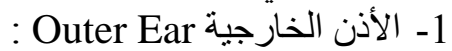

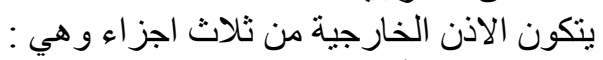

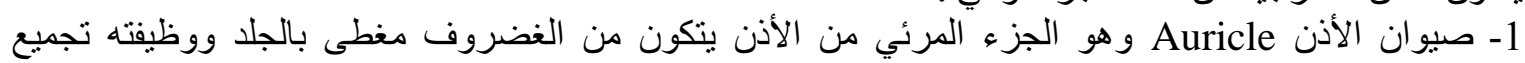

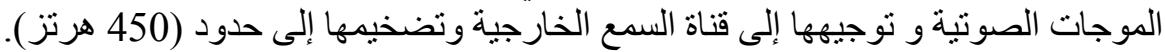

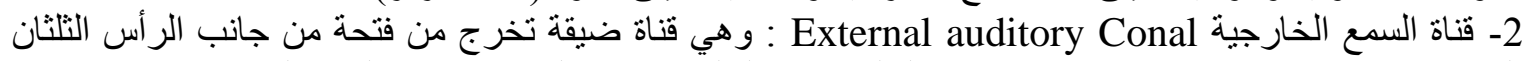

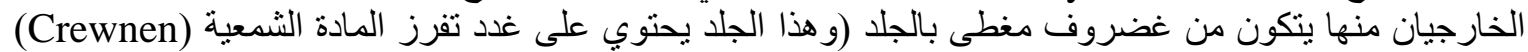

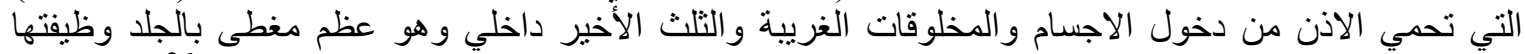

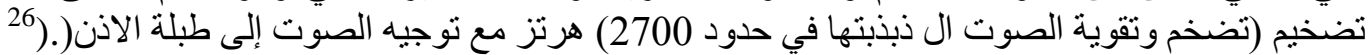

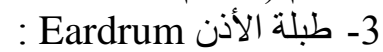
تقع عند نهاية قناة السمع الخارجية تتكون من عدة طبقات جلدية وغشاء الطبلة موجودة في الجزء العظمي من قناة

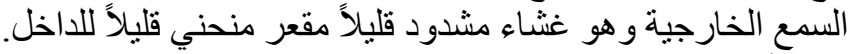

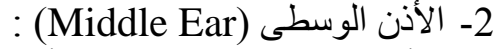

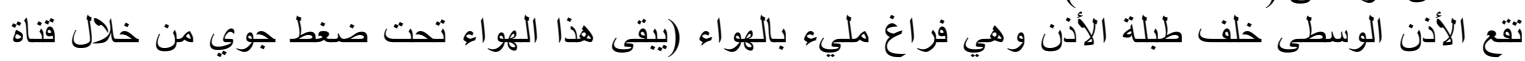

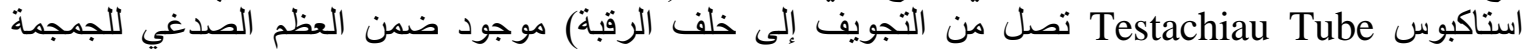

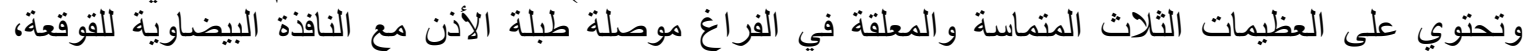

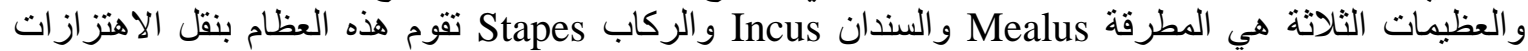
الحاصلة في طبلة الاذن إلى الأذن الداخلية أو القوقعة Cochlea وظيفة الأذن الوسطى نقل الطاقة من الهواء إلى الى

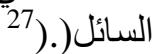

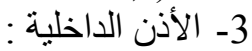

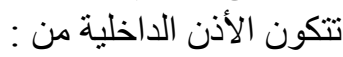

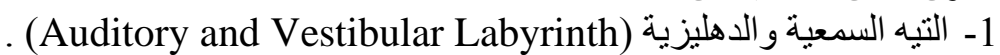

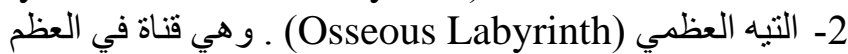

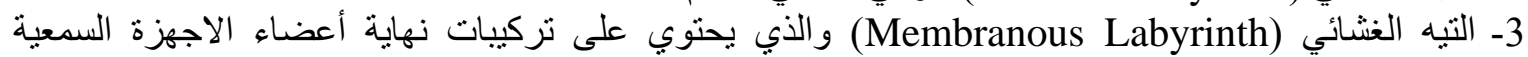
والاجهزة الدهليزية.

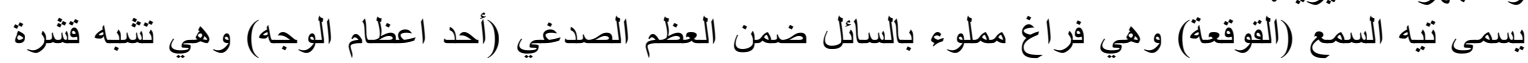

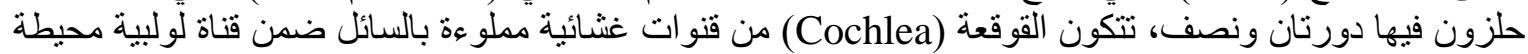

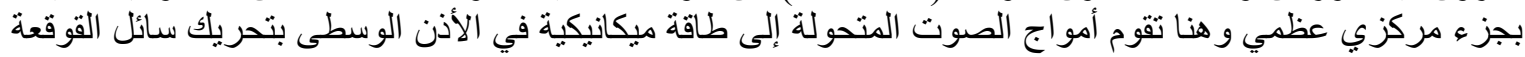

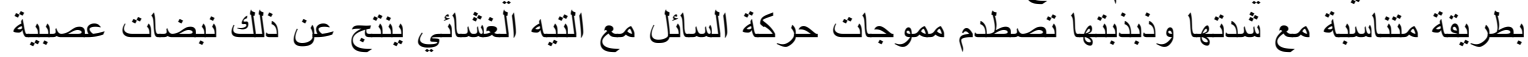
متولدة في العصب القحفي الثامن (Viith Cranial Nerve)، إذا وظيفة القوقعة تحويل موجات النياتل إلى إلى نبضات عصبية).

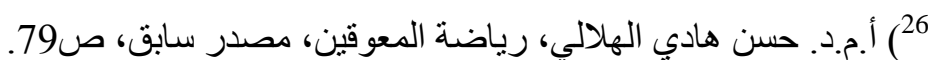

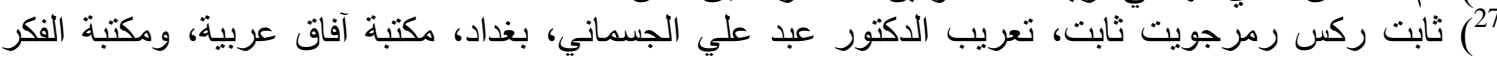

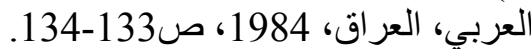
28 أربكتور حسن هادي الهلالي، رياضة المعوقين، مصدر سابق، ص40.
} 


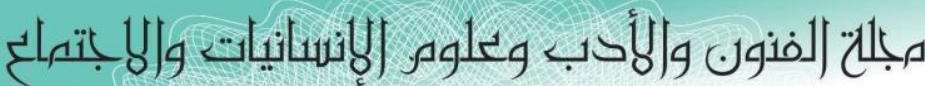

Journal of Arts, Literature, Humanities and Social Sciences

ISSN online: 2414 - 3383

ISSN print: 2616 - 3810

أيلول - سبتهبر 2019

العدد (43)

كما تحتوي الأذن الداخلية على القنوات شبه الهلالية وظبفتها الاحساس بحركات الر أس، وكذلك تحتوي على القربة و الكيس أو الجريب وظيفته الإحساس بحركات الفئ الر أس و التسار ع الخطي.

ثانياً : كيف يسمع الإنسان : الإنمئ

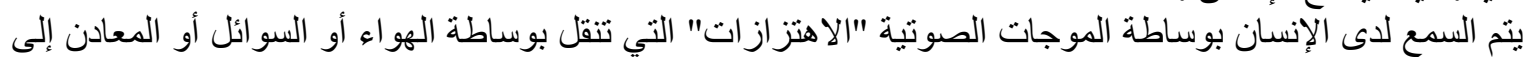

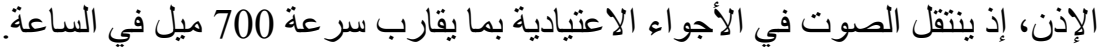

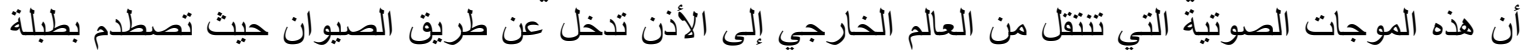

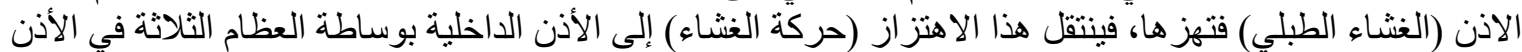

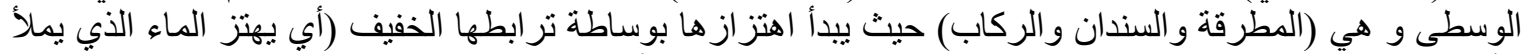

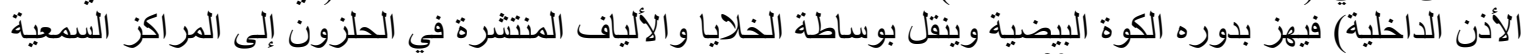

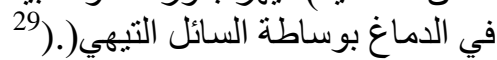

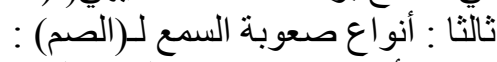

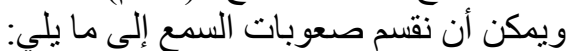

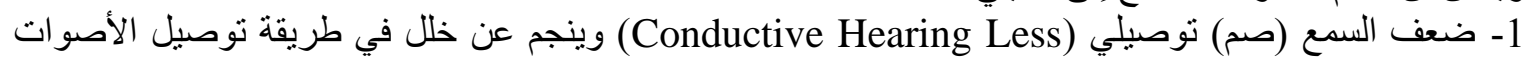

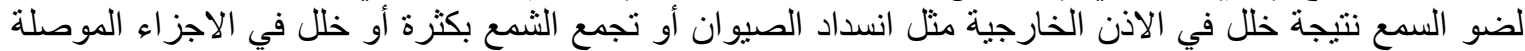

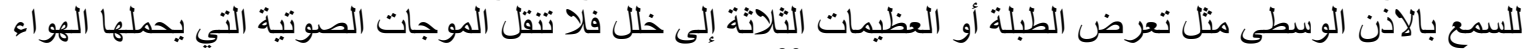

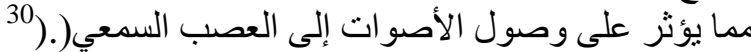

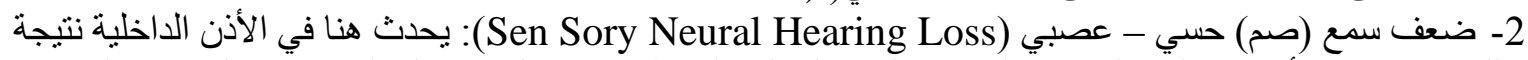
خلل في قوقعة الأذن او تلف العصب السمعي الموصل إلى الدماغ مما يعطل وصول الموجات والذي الذبذبات الصوتية

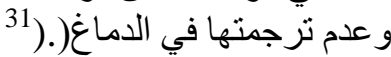

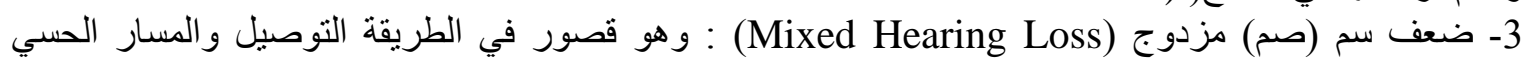
4- ضصبي : سمع (صم) مركزي : يحدث نتيجة اصابة المركز السمعي في الدماغ بخلل ما لا يمكن معه من تمبيز

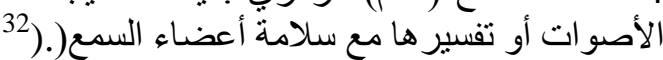

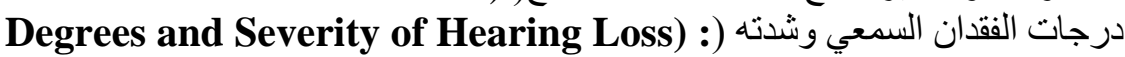

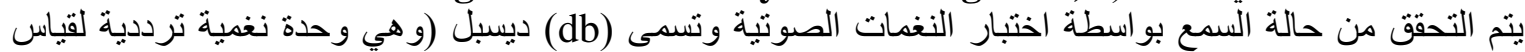

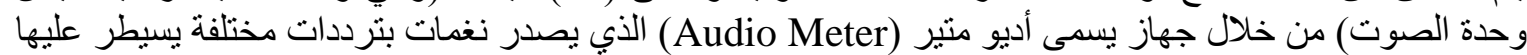

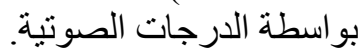

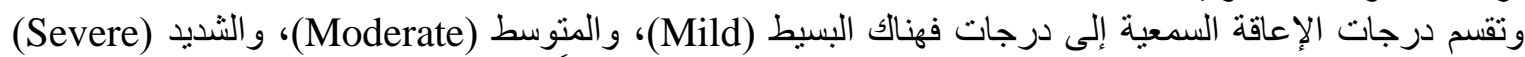

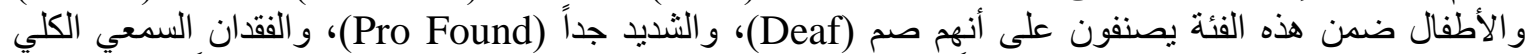
(Anacrusis) (أما مصطل المعاق سمعياً (Impaired Hearing) ليشمل كل هذه الفئات، وأيضاً هناك الفقدان الفئ

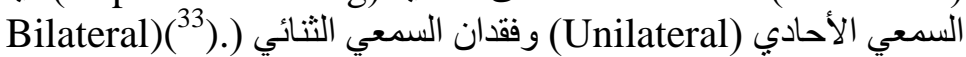

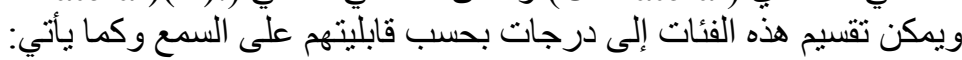

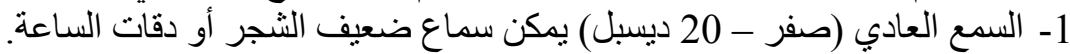

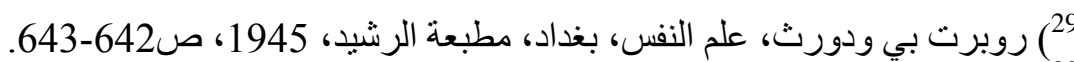

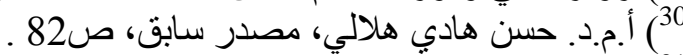
(31

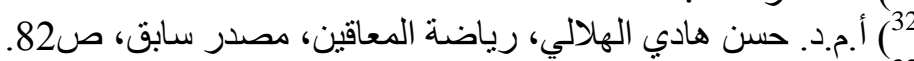
(33 المصدر نفسن. 


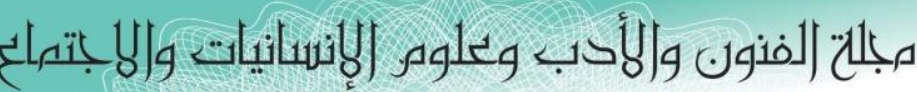
Journal of Arts, Literature, Humanities and Social Sciences

ISSN online: 2414 - 3383

ISSN print: 2616 - 3810

\section{أيلول -سبتمبر 2019}

\section{العدد (43)}

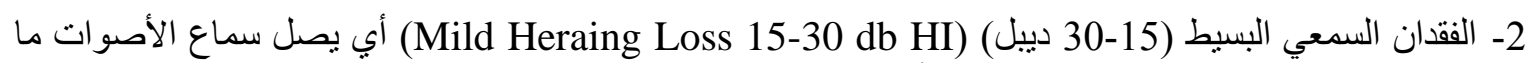

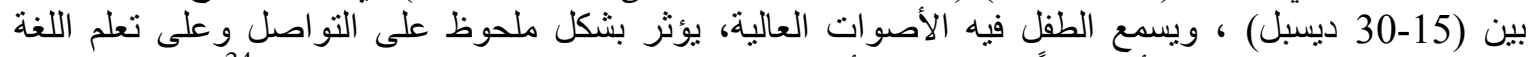

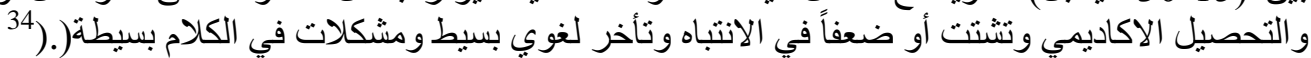

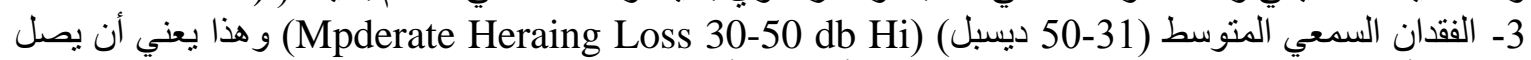

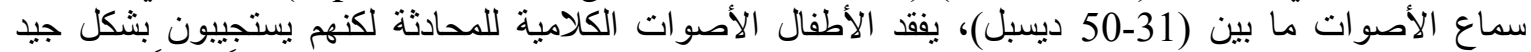
للنشاطات التربوية واللغوية باستخدام المضخمات الصوتية، يصابون بضعف أو تثنتت الانتباه وتخلفاً لغوياً ومشكلات

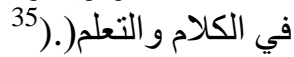

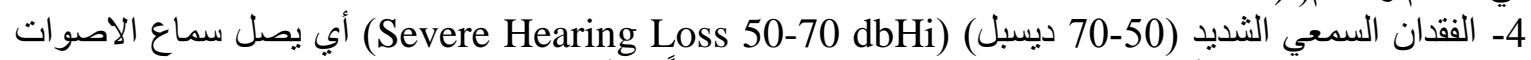

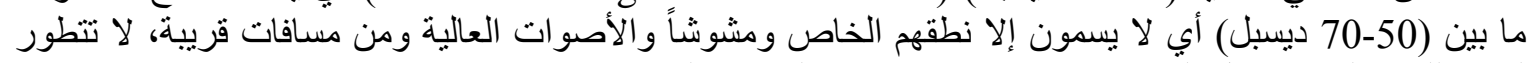

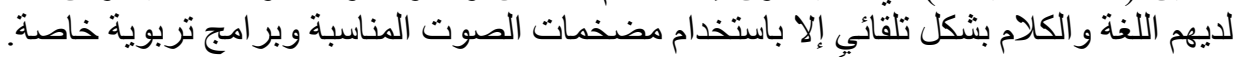

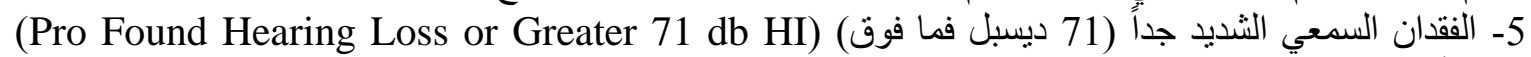

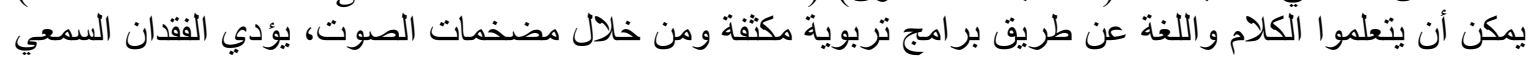

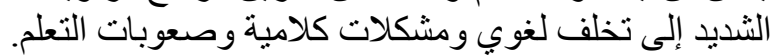

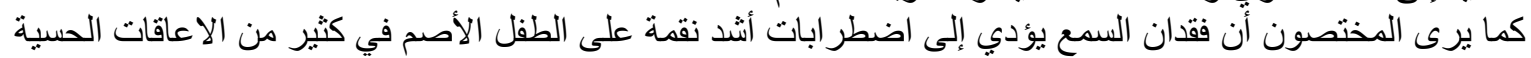

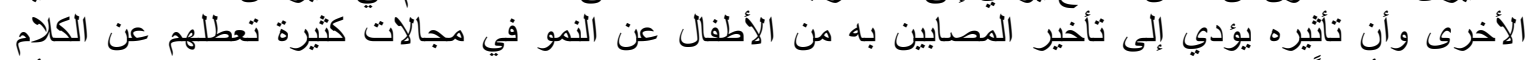

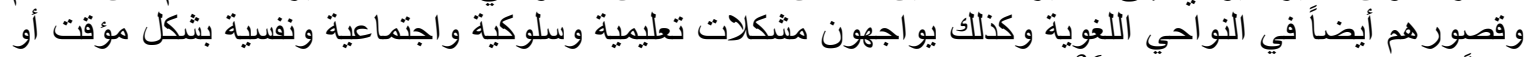

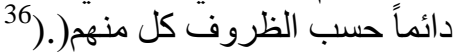

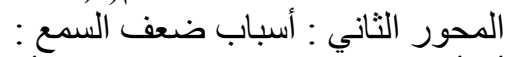

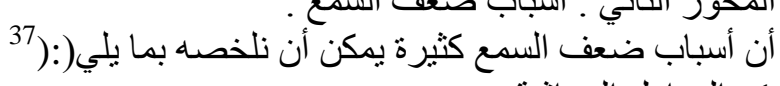

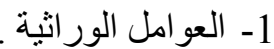
2- التثوهات الخلقية : سواء كانت هذه الثثو هات في طبلة الاذن أو في العظيمات أو في القوقعة في داخل الاذن أو

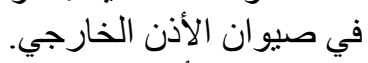

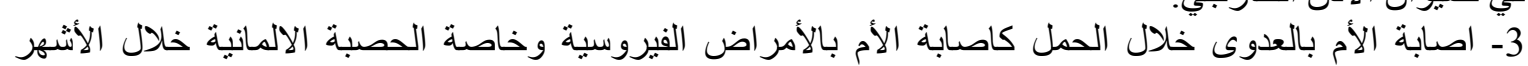

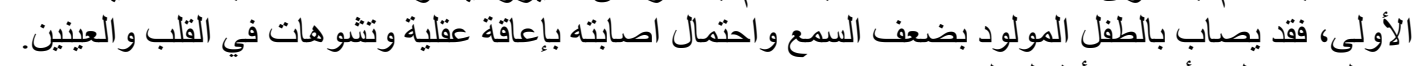

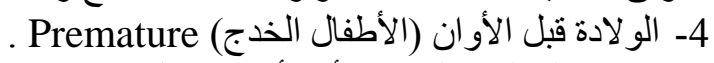
5- أصابة المولود باليرقان (أحد أمر اض الأل الدم واحد من اسبابه التهاب الكبد الفيروسي) (أبو صفار ).

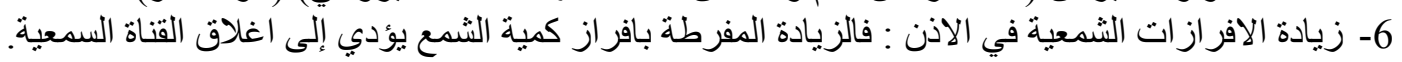

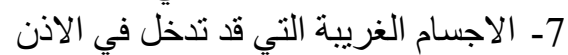

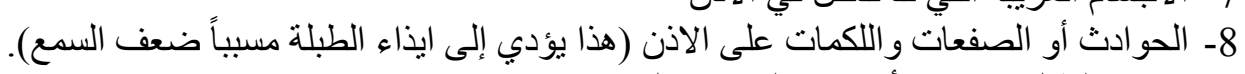

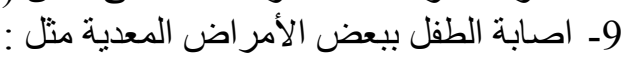

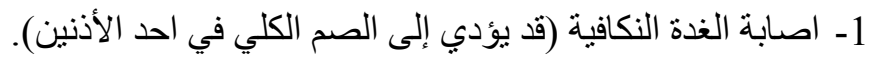

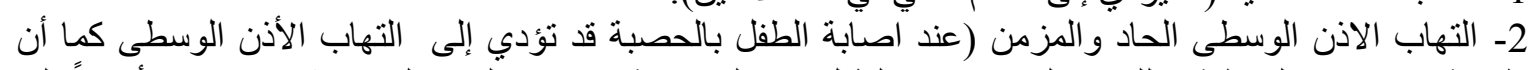

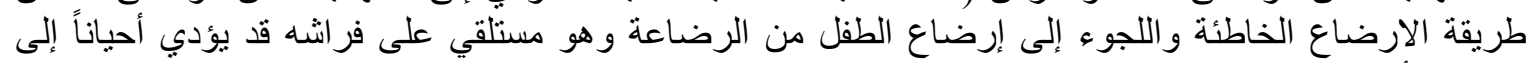

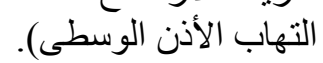

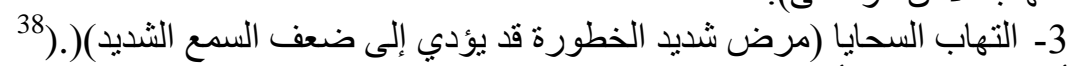

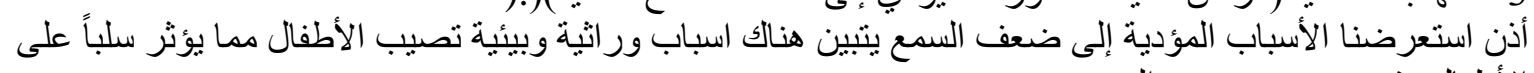
الأطفال وقد يصيبهم بضعف النمع.

$$
\text { 35 ) أ.مدد. حسن هادي الهلالي، رياضة المعاقين، ص834. }
$$

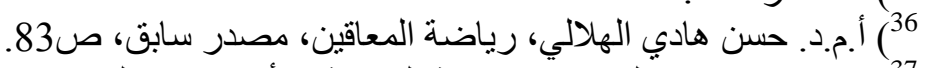

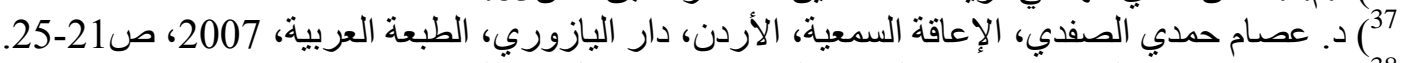

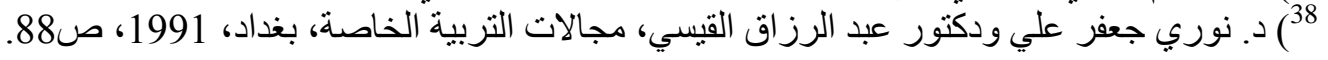




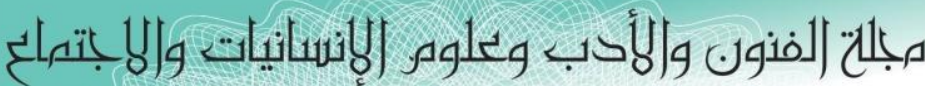

Journal of Arts, Literature, Humanities and Social Sciences

ISSN online: 2414 - 3383

ISSN print: 2616 - 3810

\section{العدد (43) ايلول - سبتهبر 2019}

تصنيف الاشخاص من الصم و البكم :

يصنف الصم و البكم إلى أربع مستويات وحسب درجات السمع المتعارف عليها و التي تسمى (Dcibel) (ديسبل) (Db)

\begin{tabular}{|c|c|c|}
\hline الملاحظات & 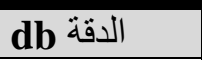 & $ت$ \\
\hline هذه الفئة لا تحتاج إلى صفوف خاصة ولكنها تحتاج إلى مساعدات صوتية. & $35-65$ & 1 \\
\hline هذه الفئة تتطلب صفوف خاصة إضافة إلى مساعدات صوتية ولغوية. & $55-69$ & 2 \\
\hline هذه الفئة تتطلب صفوف خاصنة ومساعدات صوتية ولغوية. & $70-89$ & 3 \\
\hline هذه الفئة تنطلب صفوف خاصة و مساعدات صوتية ولغوية. & 90 فما فوق & 4 \\
\hline
\end{tabular}

المحور الثالث : الأنشطة الرياضبة التي تنتاسب مع الصم و البكم : يمارس رياضيو الصم مزاولة هو اياتهم الرياضية في نهاية القرن التاسع عشر الإية حيث قامت مدرسة الصم في ولاية

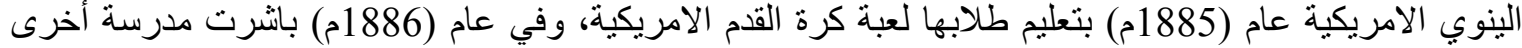

للصم في ولاية او هايو بتعليم طلابها لعبة البيسبول وكان ذلك مدخل لتنظيم بطولات محلية ودولية للصم.

Comate Internaional des Sport Des Surds (CISS)

إذ كان مقر ها في فرنسا.

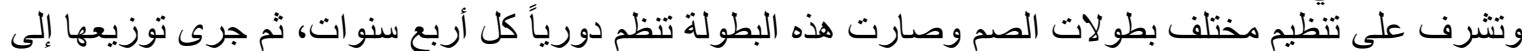

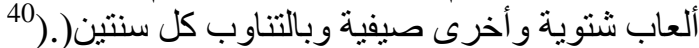

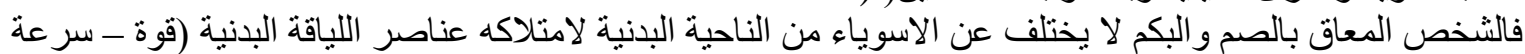

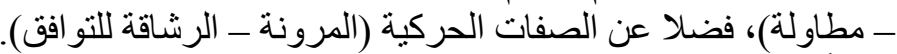

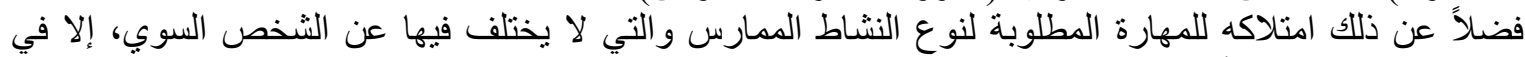

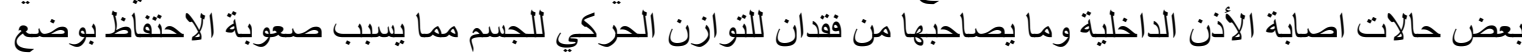
الجسم وتاثير ذلك على مستوى اللياقة البدنية.

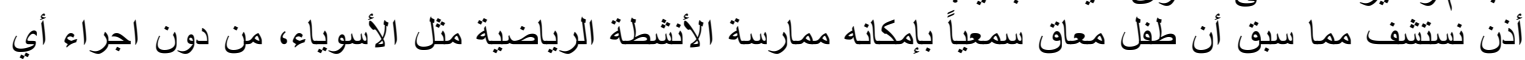
تعديلات أو تغيير هندسة المكان و الأدوات لكي يقوم بأداء كل أنواع الأنشطة الرياضية الترويحية بكل وجد وحيوية

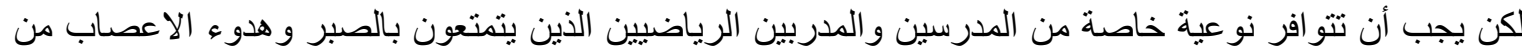

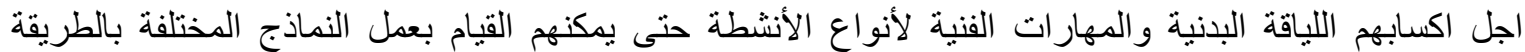
الصحيحة ليتسنى للمعاقين منهم الحركة وتقليد المدرس عند اداء المهارات المختلفة مع الأخذ بنظر الاعتبار أنهم فئة لأنة

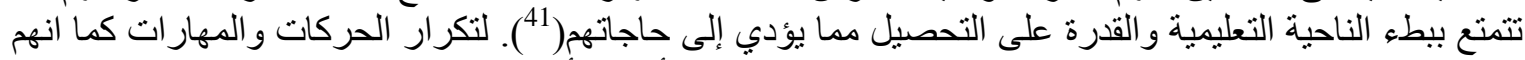

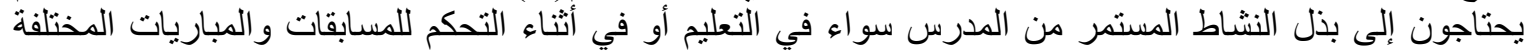

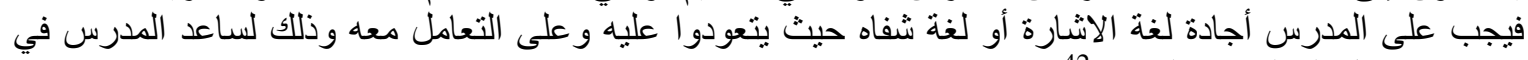

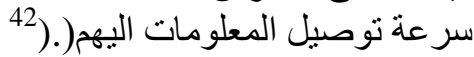

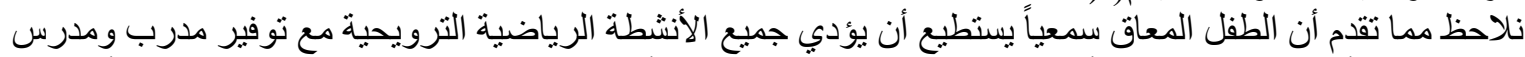

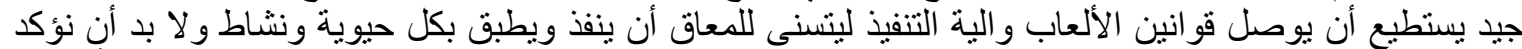
على نقطة مهمة بالموضو ع و هو أن استعداد الطفل المعاق سمعيا على التعليم وتدريب وحبه للرياضة هذا أبضاً عامل

39 ) عصام حمدي الصفدي، الإعاقة السمعية، مصدر سابق، ص65.

40) Jump. Up "Skipper Francis at Thames ster New Zealud" Paperspast, govt.n z. 170, tober 2011, P.6

$\left.{ }^{41}\right)$ Jump. Up, "International Committee of Sport fo the Deaf" Retrieved 12, September 2010, P.1-4. 42) سكوت جوردان، تدريب ذوي الاحتياجات الخاصة، ترجمة عبد الحكيم جواد مطر ، الامانة العامة لمجلس التعاون

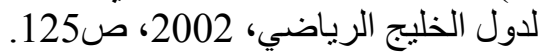




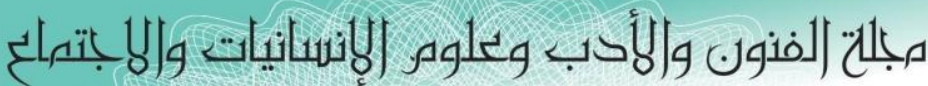

Journal of Arts, Literature, Humanities and Social Sciences

ISSN online: 2414 - 3383

ISSN print: 2616 - 3810

أيلول - سبتهبر 2019

العدد (43)

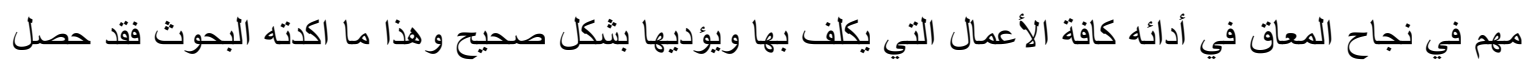

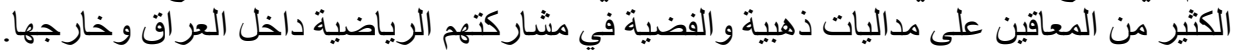

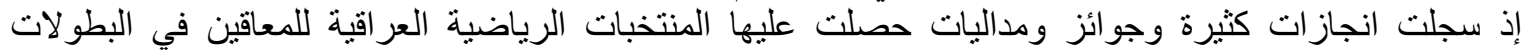

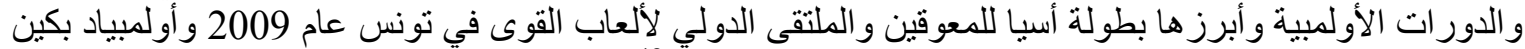

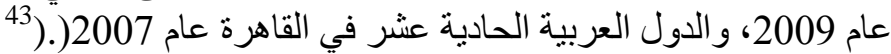

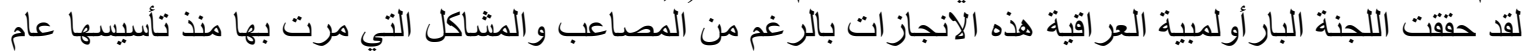
2003 لتحل محلها الاتحاد العر اقي لرياضة الرئة المعاقين. الألعاب الرياضية الخاصة للمعاقين سمعياً : هناك عدة أنشطة رياضية يختص بها لها المعاقين سمعياً وهي :

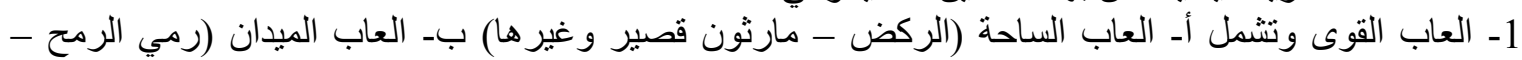

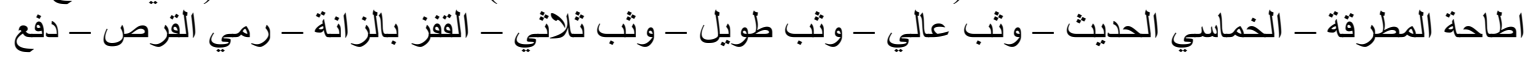

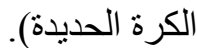

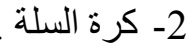

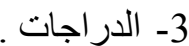

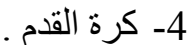

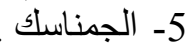
6- كرة اليد.

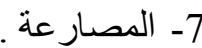

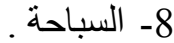

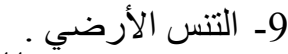

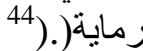
$-10$

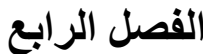

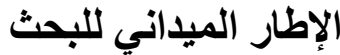

في هذا الفصل سيتم عرض المحاور التالية وهي : 1- تصميم العينة الاحصائية : على البحث عند تصميم التيم العينة الاحصائية أن يعتمد كيفية أخذ العينة وحجمها وطرق

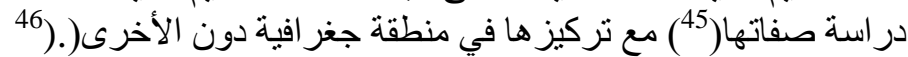

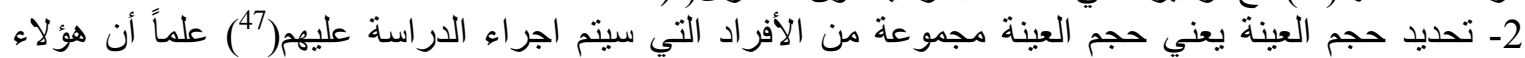

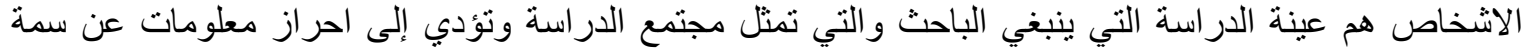

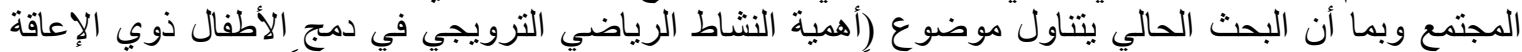

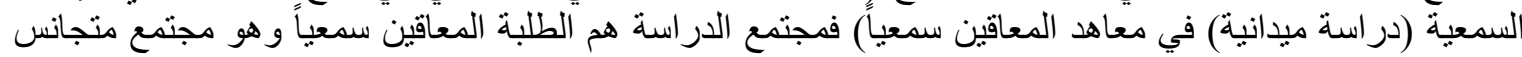

43) روح العراق ملتقى العر اقيين و العرب، في قمم الأمل لذوي الاحتياجات الخاصة، العراق، وزارة العمل و الثؤون

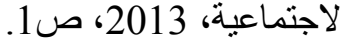
44 الاجثر علي الجمالي و أخرون، منهاج رياضة المعاقين سمعياً، العراق، و زارة العمل و الثؤون الاجتماعية، قسم

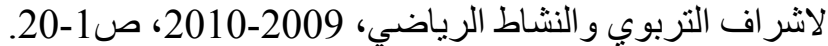

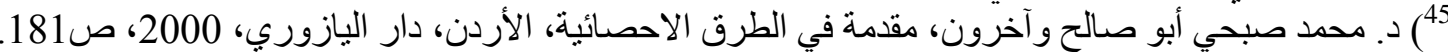

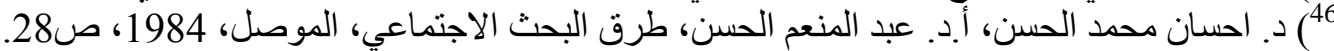

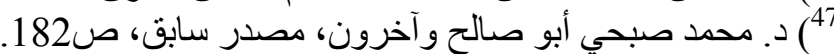




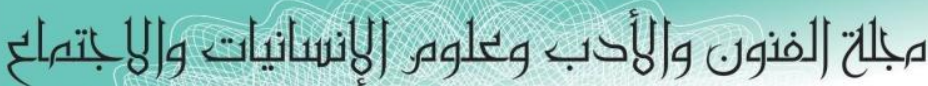

Journal of Arts, Literature, Humanities and Social Sciences

ISSN online: 2414 - 3383

ISSN print: 2616 - 3810

\section{العدد (43) ايلول -سبتمبر 2019}

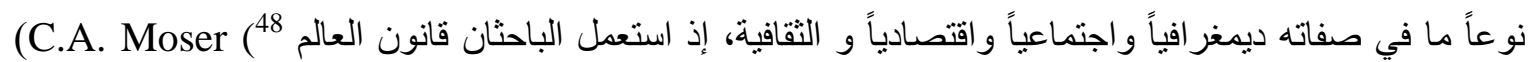

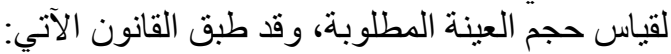

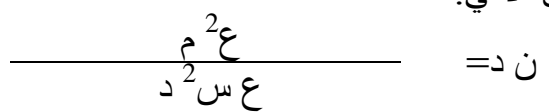

علماً إن

ع س2 د=

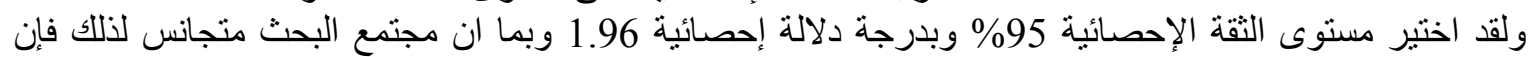

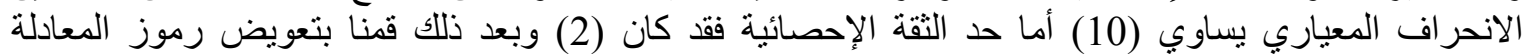
الإحصائية بالأرقام للحصول على حجم العينة المختارة وكما يأني:

$$
\frac{(2)^{2}}{1.96}=د^{2}
$$$$
\text { إذاً: ن د = } 50=\frac{(10)^{2}}{2} \quad \text { حجم العينة }
$$

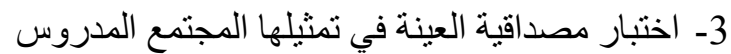

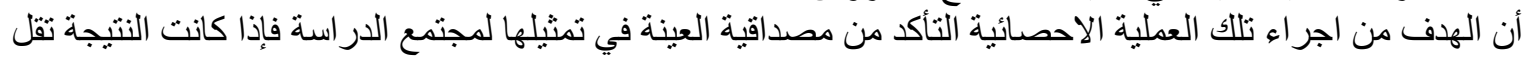

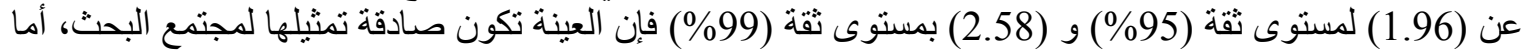

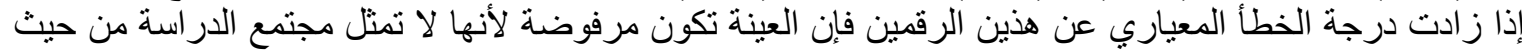
الصفات و الخصائص وفي ذللك تم تطبيق القانون الآتي:

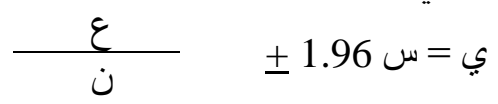

$$
\text { و عوضنا بعد ذلك رموز المعادلة بالأرقام وكما يلي: }
$$

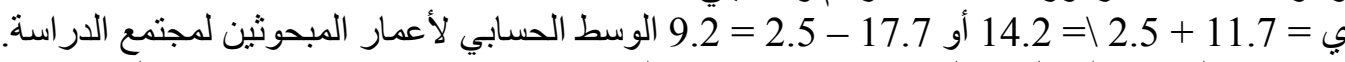
و"اعتمدت الباحثة على القيمة الموجبة (14.2) واستعملت قانون (T.Test) اختبار مصداقية العينة في تمثيلها لمجتمع العين

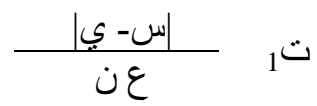

$$
\begin{aligned}
& \text { علما أن عن }=1.3 \frac{9.6}{50}=\frac{\varepsilon}{\dot{u}}= \\
& \text { ت } \\
& =1 \frac{|12.9-14.2|}{1.3} \quad ت
\end{aligned}
$$
الدراسة والقانون على النحو الآتي:

ت=1 وبعد إجر اء أهمية الفرق المعنوي بين الوسط الحسابي لأعمار العينة والوسط الحسابي للأعمار مجتمع الدراسة، لم نجد هناك فرق معنوياً بينهما على مستوى ثقة (95\%) لأن نتيجة الأنية الأختبار (1) من القيمة الجدولية (1.96) و عليه فأن العينة المختارة كانت صنادقة في تمثنبالها لمجتمع البحث.

${ }^{48}$ () Claus Moser, and kaltou, survey methods in social luvestigatiou London, Hein Emann Edueational Books (LTD), 2ed , 1975, P.146-148. 


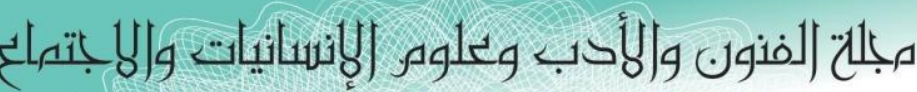
Journal of Arts, Literature, Humanities and Social Sciences

ISSN online: 2414 - 3383

ISSN print: 2616 - 3810

\section{أيلول - سبتهبر 2019}

العدد (43)

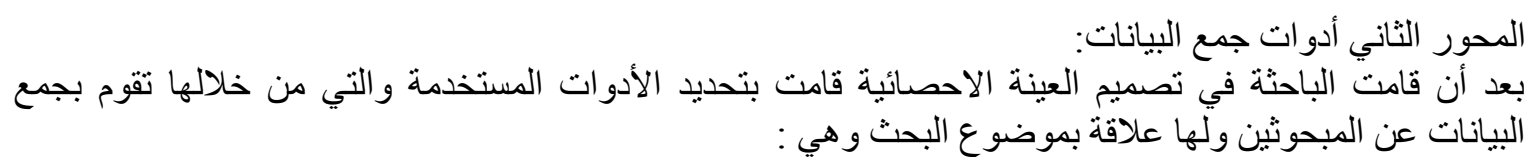
1- استمارة الاستبانة (Question Naira).

2- 2 المقابلة (Interview).

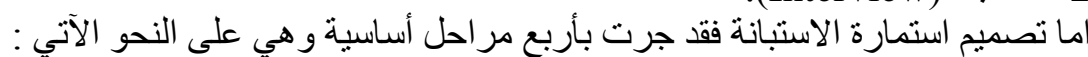

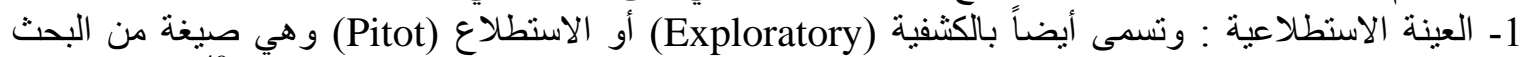

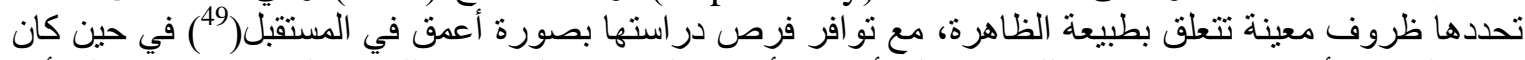

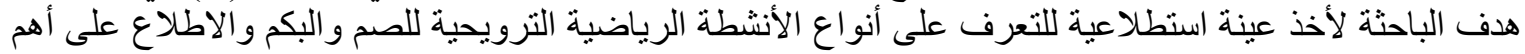

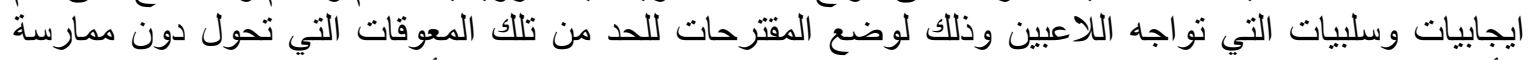

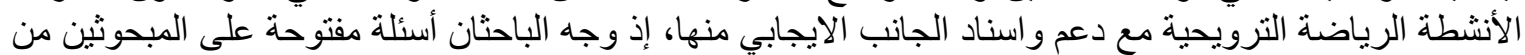
خلال استمارة ومن ثم ثم استلام الاجابة وبعدها حولت تلإنك الاجابة إلى الفقرات ثم الافادة منها في تصميم استمارة

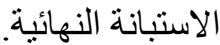

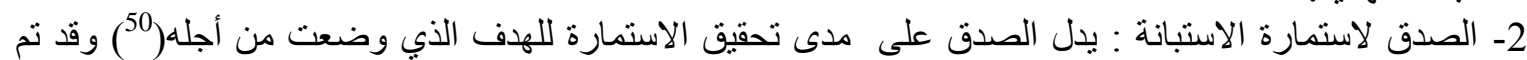

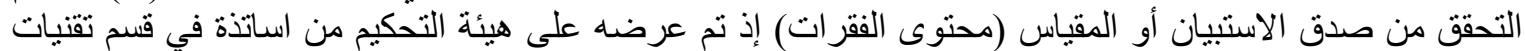

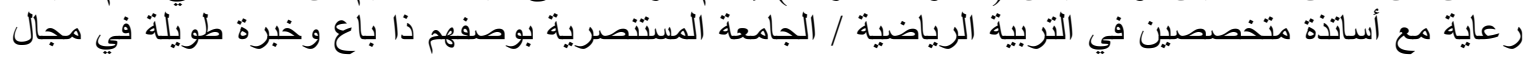

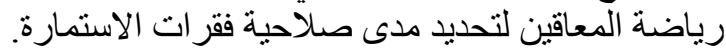

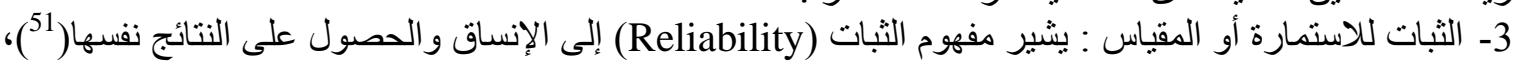

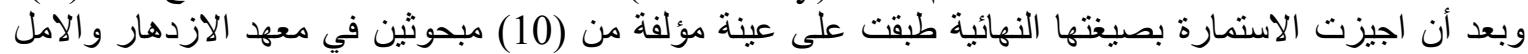

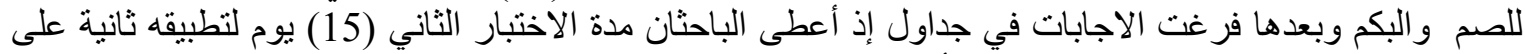

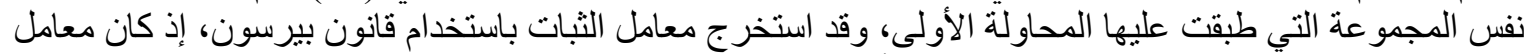

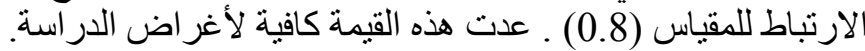

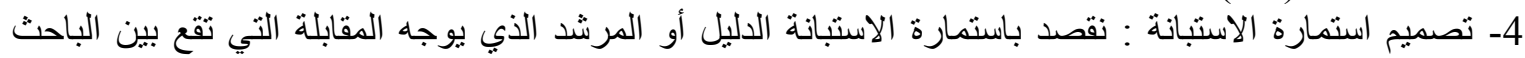

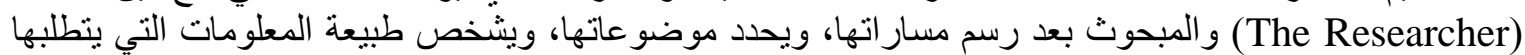

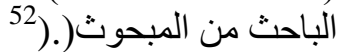

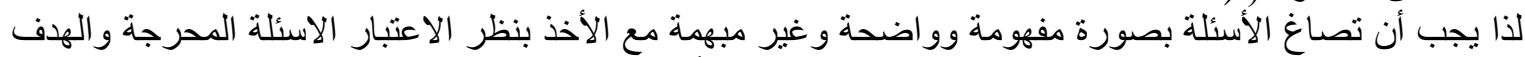

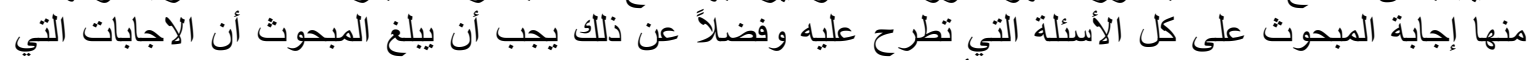

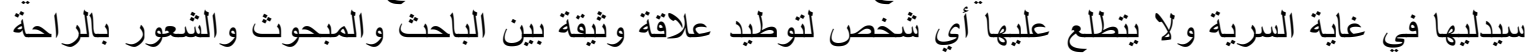

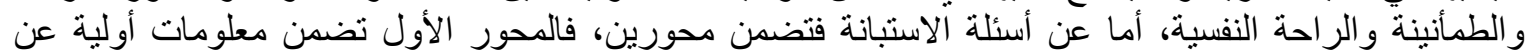

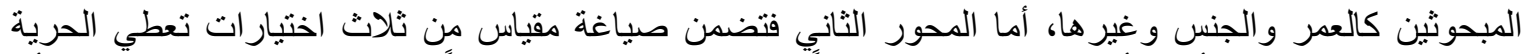

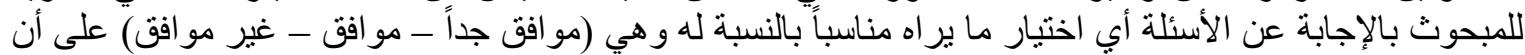

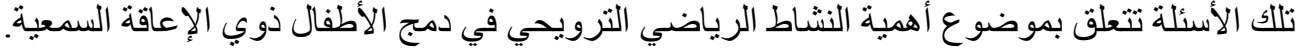

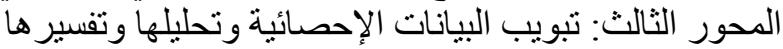

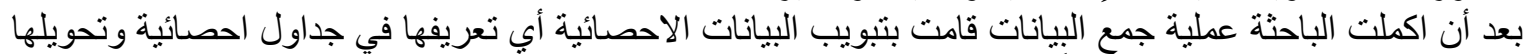

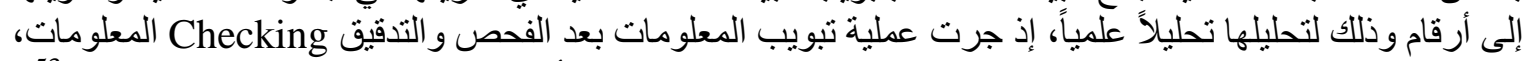

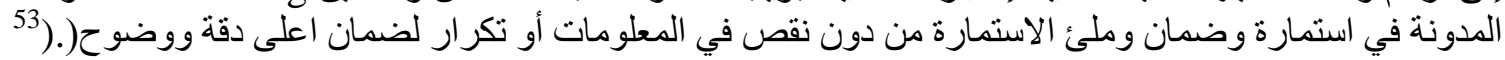

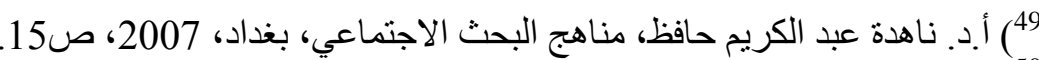

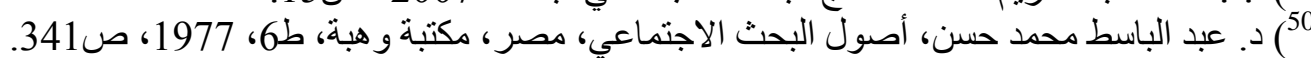

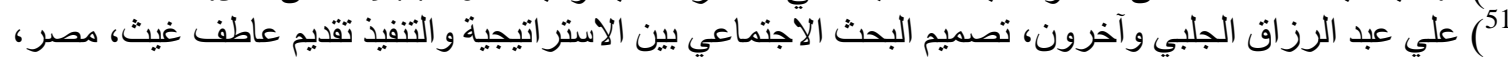

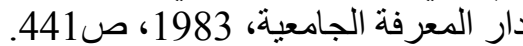

${ }^{52}$ () C. A. Moser, Survey Ment, hod in social, investigation Hein-mon-London, 1967, 


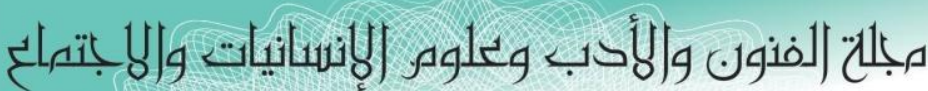

Journal of Arts, Literature, Humanities and Social Sciences

ISSN online: 2414 - 3383

ISSN print: 2616 - 3810

\section{العدد (43) ايلول -سبتمبر 2019}

وبعد عملية الترميز Coding و هي عملية تحويل الاجابات إلى أرقام، مما يساعدنا على تبويب البيانات و ادخالها في

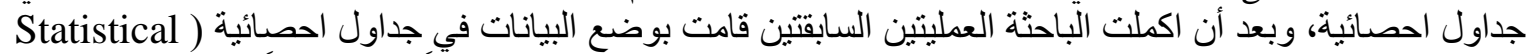
(Tables لكي تهيا لتفسير ها وتحليلها، وبعد تصنيف وتحليل البيانات وتفسير ها علمياً وموضو عياً بحيث تخدم أهداف الفيات

\section{الفصل الخامس}

يتضمن هذا الفصل محورين يتضمن المحور الأول عرض البيانات الأساسية لوحدات العينة والتي بواسطتها تم أخذ الخدات

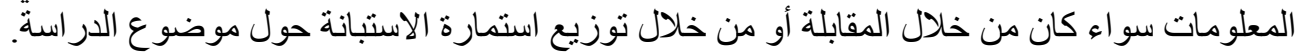
المحور الأول : البيانات الاساسية لوحدات العات العينة.

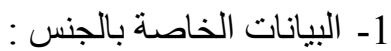

يتضح من دراستنا الميدانية إلى أن عدان أند الذكور في العينة قد بلغ (35) مبحوث من مجموع (50) (150) مبحوث وبنسبة

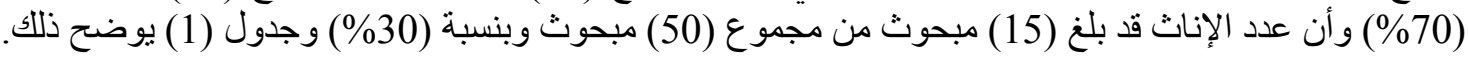
جدول (1) يوضح نوزيع الجنس

\begin{tabular}{|c|c|c|}
\hline النسبة المئوية & التكر ار & الجنس \\
\hline $70 \%$ & 35 & ذكور \\
\hline $30 \%$ & 15 & إناث \\
\hline $100 \%$ & 50 & المجموع \\
\hline
\end{tabular}

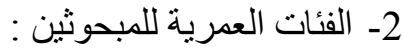

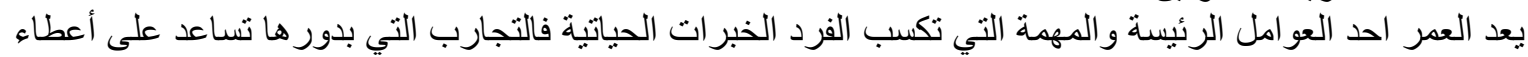

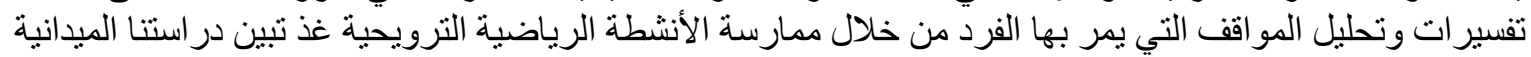

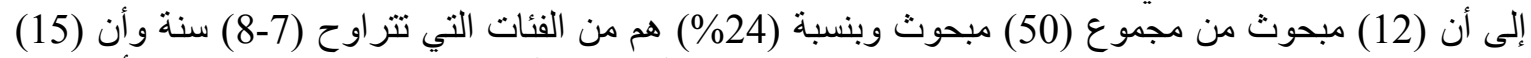

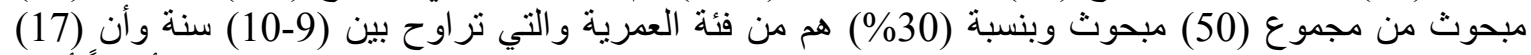

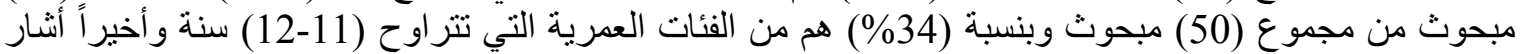

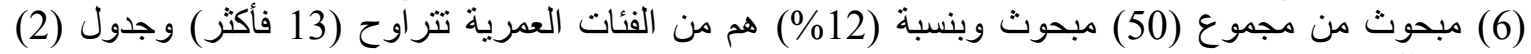
يوضح ذللك.

\begin{tabular}{|c|c|c|}
\hline النسبة المئوية & التكر ار & الفئات العمرية \\
\hline $24 \%$ & 12 & $7-8$ \\
\hline $30 \%$ & 15 & $9-10$ \\
\hline $34 \%$ & 17 & 11-12 \\
\hline $12 \%$ & 6 & 13 فأكثر \\
\hline $100 \%$ & 50 & المجموع \\
\hline
\end{tabular}

3- بيانات خاصة عن نوع النشاط الرياضي الترويحي :

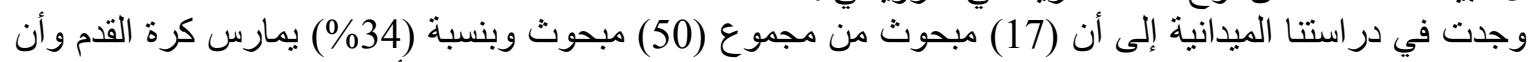

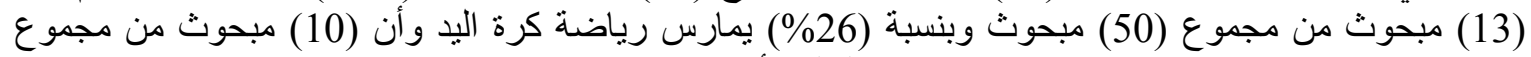

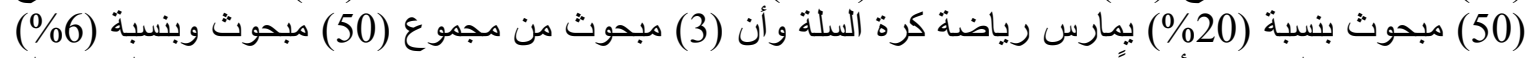

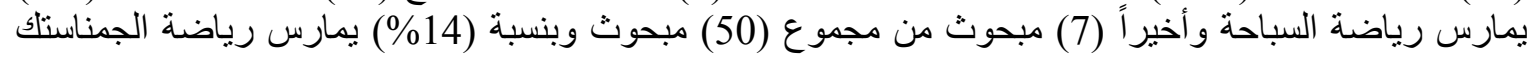
وجدول (3) يوضح ذلك.

53 د. د. علي سليم العلاونة، أساليب البحث في العلوم الإدارية، دار الفكر، ط1، 1996، ص191. 


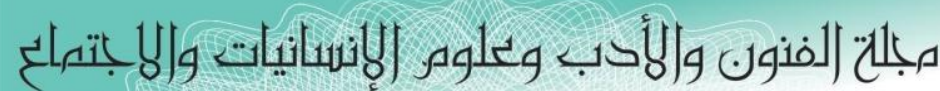

Journal of Arts, Literature, Humanities and Social Sciences

ISSN online: 2414 - 3383

ISSN print: 2616 - 3810

العدد (43) ايلول - سبتمبر 2019

جدول (3) يوضح نوع النشاط الرياضي الترويحي

\begin{tabular}{|c|c|c|}
\hline النسبة المئوية & التكر ار & نوع النشاط \\
\hline $34 \%$ & 17 & كرة القدم \\
\hline $26 \%$ & 13 & كرة اليد \\
\hline $20 \%$ & 10 & كرة السلة \\
\hline $6 \%$ & 3 & السباحة \\
\hline $14 \%$ & 7 & الجمناستلك \\
\hline $100 \%$ & 50 & وع \\
\hline
\end{tabular}

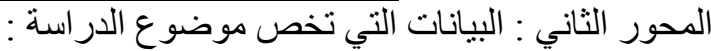

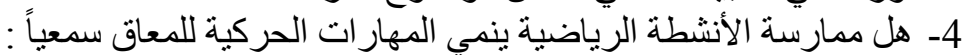

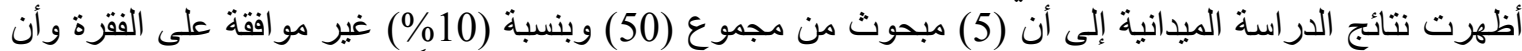

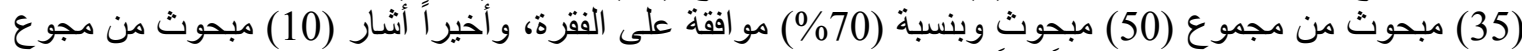

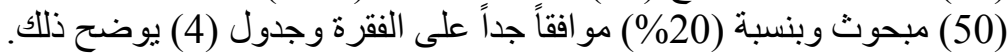

جدول (4) بوضح هل ممارسة الأنشطة الرياضية ينمي المهار ات الحركية للمعاق سمعياً

\begin{tabular}{|c|c|c|}
\hline النسبة المئوية & التكر ار & هل ممارسة الأنشطة \\
\hline $10 \%$ & 5 & غير موافقة \\
\hline $70 \%$ & 35 & مو افقة \\
\hline $20 \%$ & 10 & مو افقة جداً \\
\hline $100 \%$ & 50 & المجموع \\
\hline
\end{tabular}

5- هل ممارسة الأنشطة الرياضية تهدف إلى التنمية الثاملة للفرد المعاق سمعياً نفسياً واجتماعياً وعقلياً:

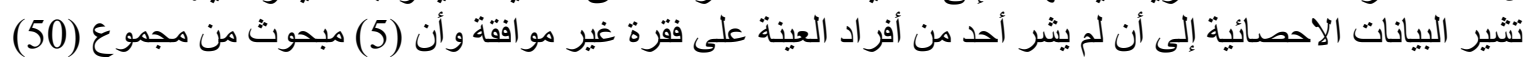

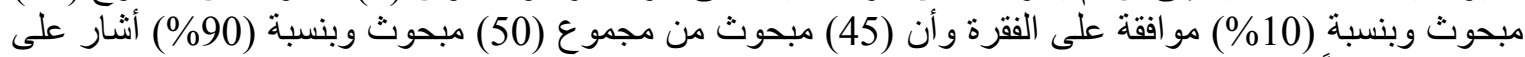
فقرة مو افقة جداً وجدول (5) يوضح ذلان. جدول (5) يوضح هل أن ممارسة الأنشطة الرياضية يهدف إلى التنمية الثاملة للفرد المعاق سمعياً نفسياً و اجتماعياً و عقلياً النياً

\begin{tabular}{|c|c|c|}
\hline النسبة المئوية & 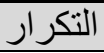 & ممارسة أنشطة تنمي جو انب نفسياً \\
\hline- & - & غير مو اققة \\
\hline $10 \%$ & 5 & مو افقة \\
\hline $90 \%$ & 45 & مو افقة جداً \\
\hline $100 \%$ & 50 & المجموع \\
\hline
\end{tabular}

6- هل تمارس النشاط الرياضي الترويحي في وقت محدند :

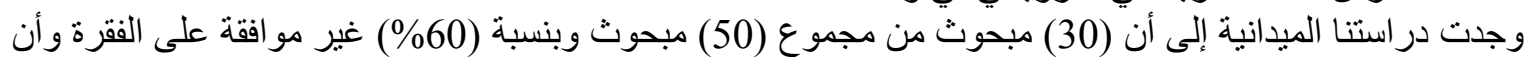
(9) مبحوث من مجموع (50) مبحوث وبنسبة (18\%) (18) مو افقة على الفقرة وأن (11) مبحوث من مجمو ع ع (50) مبحوث وبنسبة (22\%) مو افقة جداً والجدول (6) يوضح ذلك. 


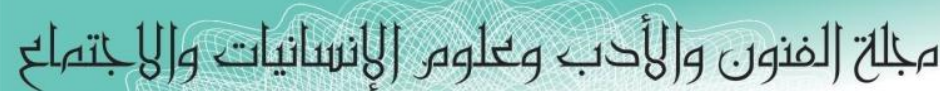
Journal of Arts, Literature, Humanities and Social Sciences

ISSN online: 2414 - 3383

ISSN print: 2616 - 3810 العدد (43) ايلول -سبتمبر 2019

جدول (6) يوضح هل تمارس النشاط الرياضي الترويحي في وقت محدد

\begin{tabular}{|c|c|c|}
\hline النسبة المئوية & التكر ار & هل تمارس النشاط الرياضي في \\
\hline $60 \%$ & 30 & غير مو افقة \\
\hline $18 \%$ & 9 & مو افقة \\
\hline $22 \%$ & 11 & مو افقة جداً \\
\hline $100 \%$ & 50 & المجموع \\
\hline
\end{tabular}

7- هل أن إدارة المعهد لها دور في التشجيع لممارسة الأنشطة الرياضية الترويحية :

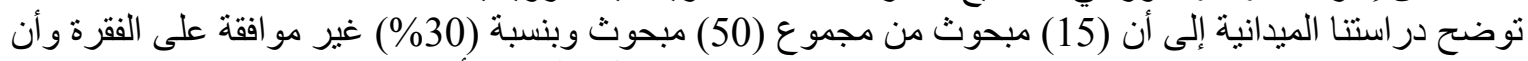

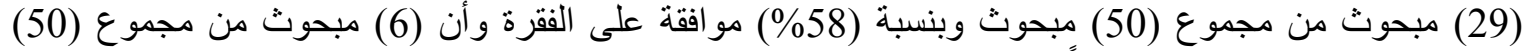
مبحوث وبنسبة (12\%) مو افقة جداً على الفقرة و الجدول (7) مبو (7) موضح ذلك.

جدول (7) يوضح هل أن إدارة المعهد لها دور في التشجيع لممارسة الأنشطة الرياضية الترويحية

\begin{tabular}{|c|c|c|}
\hline النسبة المئوية & التكر ار & هل أن إدارة المعهد \\
\hline $30 \%$ & 15 & غير مو افقة \\
\hline $58 \%$ & 29 & مو افقة \\
\hline $12 \%$ & 6 & مو افقة جداً \\
\hline $100 \%$ & 50 & المجموع \\
\hline
\end{tabular}

8- عدم تو افر المستلزمات و التجهيزات و القاعات الرياضية : تشير دراستنا المبدانية إلى أن (6) مبحوث من مجموع (50) مبحوث وبنسبة (12\%) غير موافقة على الفقرة على (12) مئى

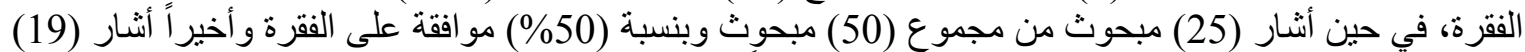

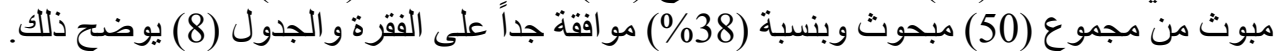

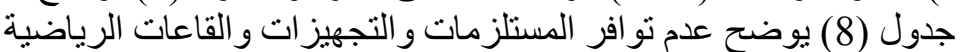

\begin{tabular}{|c|c|c|}
\hline النسبة المئوية & التكر ار & عدم تو افر المستلزمات \\
\hline $12 \%$ & 6 & غير مو افقة \\
\hline $50 \%$ & 25 & مو افقة \\
\hline $38 \%$ & 19 & مو افقة جداً \\
\hline $100 \%$ & 50 & المجموع \\
\hline
\end{tabular}

9- لا يوجد معلم مختص بتدريب الطلبة لممارسة الأنشطة الرياضية الترويحية:

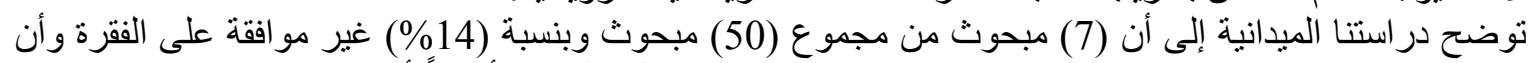

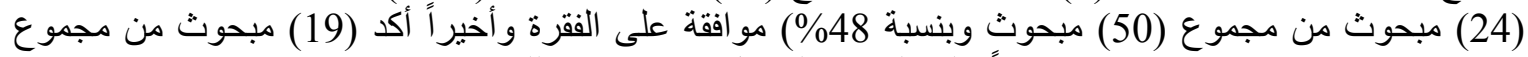

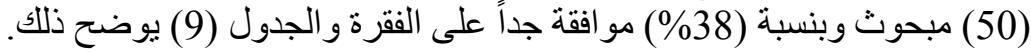
جدول (9) يوضح لا يوجد معلم مختص لتدريب الطلبة على ممارسة الأنشطة الرياضية الترويحية

\begin{tabular}{|c|c|c|}
\hline النسبة المئوية & التكر ار & هل يو جد معلم \\
\hline $14 \%$ & 7 & غير مو افقة \\
\hline $48 \%$ & 24 & مو افقة \\
\hline $38 \%$ & 19 & مو افقة جداً \\
\hline $100 \%$ & 50 & المجموع \\
\hline
\end{tabular}


مبلحت (لفنون والأدب وعلوه الإنسانيات والبانتهاع

Journal of Arts, Literature, Humanities and Social Sciences

ISSN online: 2414 - 3383

ISSN print: 2616 - 3810

\section{العدد (43) ايلول - سبتمبر 2019}

10- عدم وجود الدعم المادي و المعنوي من قبل وزارة الثباب :

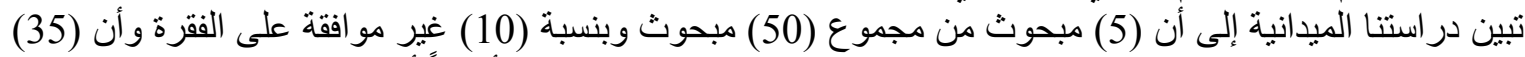

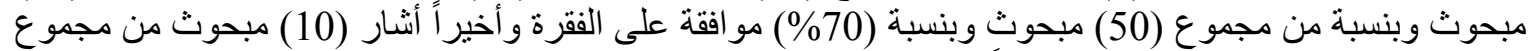

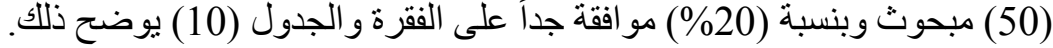

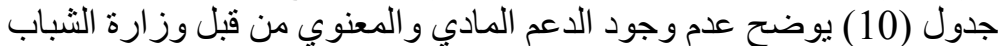

\begin{tabular}{|c|c|c|}
\hline النسبة المئوية & التكر ار & عدم وجود الدعم \\
\hline $10 \%$ & 5 & غير مو افقة \\
\hline $70 \%$ & 35 & مو افقة \\
\hline $20 \%$ & 10 & مو افقة جداً \\
\hline $100 \%$ & 50 & المجموع \\
\hline
\end{tabular}

11- عدم وجود وسائط لنقل اللاعبين للمشاركة في الأنشطة الرياضية النرويحية:

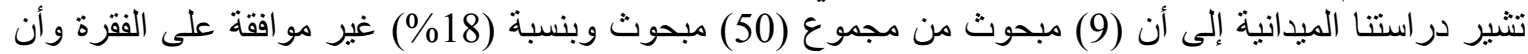

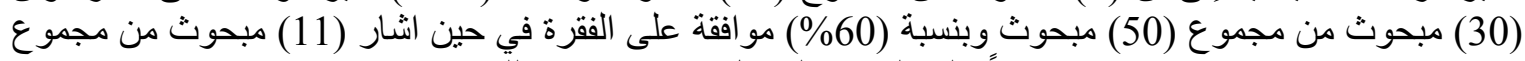

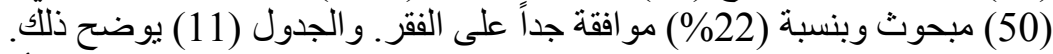

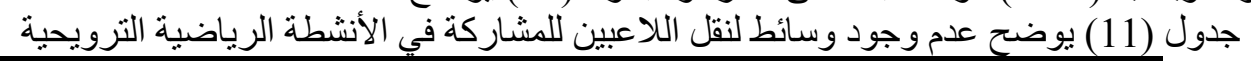

\begin{tabular}{|c|c|c|}
\hline النسبة المئوية & الت التكرار & عدم وجود وسائط لنقل اللاعبين \\
\hline $18 \%$ & 9 & غير مو افقة \\
\hline $60 \%$ & 30 & مو افقة \\
\hline $22 \%$ & 11 & مو افقة جداً \\
\hline $100 \%$ & 50 & المجموع \\
\hline
\end{tabular}

جدول (12) يوضح العو امل حسب التسلسل المرتبي (تنازلبا) و الوزن النسبي للعينة بحسب قانون البروفسور جوزيف كهل

\begin{tabular}{|c|c|c|c|}
\hline 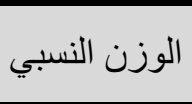 & 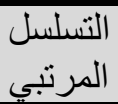 & العو امل & $ت$ \\
\hline $96.6 \%$ & 1 & همعياً نفسياً واجتماعياً الأنشطة الرياضية تهية تهف إلى التنمية الثاملة للفرد المعاق & 1 \\
\hline $75.3 \%$ & 2 & عدم تو افر المستلزمات و التجهيزات و القاعات الرياضية. & 2 \\
\hline $74.6 \%$ & 3 & لالترويحبة. معلم مختص بتدريب الطلبة لممارسة الأنشطة الرياضية & 3 \\
\hline $68 \%$ & 6 & الترويحية. & 4 \\
\hline $70 \%$ & 5 & عدم وجود الدعم المادي و المعنوي من قبل وز ارة الشباب. & 5 \\
\hline $70 \%$ & 4 & هل ممارسة الأنشطة الرياضية تتمي المهار ات الحركية للمعاق سمعياً. & 6 \\
\hline $60.6 \%$ & 7 & هل الترويحية. & 7 \\
\hline $54 \%$ & 8 & هل تمارس النشاط الرياضي في وقت محدد. & 8 \\
\hline
\end{tabular}

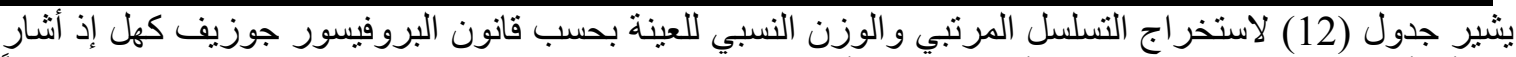

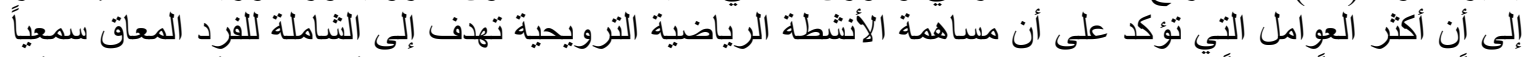

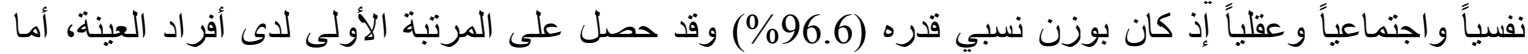
العامل عدم توافر المستلزمات والتجهيزات والقاعات الرياضية فكان بوزن نسبي قدره (75.3\%) وحصل على لإنى 


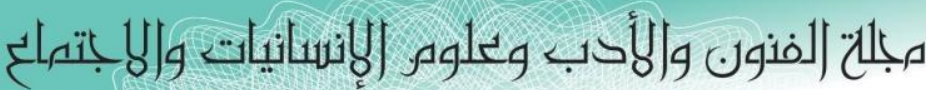

Journal of Arts, Literature, Humanities and Social Sciences

ISSN online: 2414 - 3383

ISSN print: 2616 - 3810

\section{العدد (43) ايلول -سبتمبر 2019}

المرتبة الثانية في حين حصل العامل لا يوجد معلم مختص بتدريب الطلبة لممارسة الأنشطة الرياضية الترويحية فكان

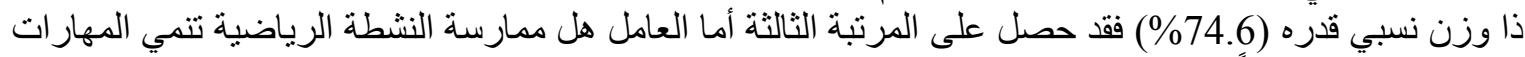

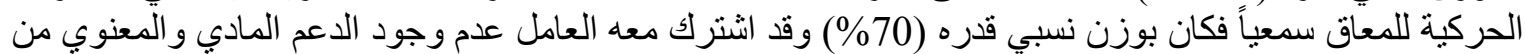

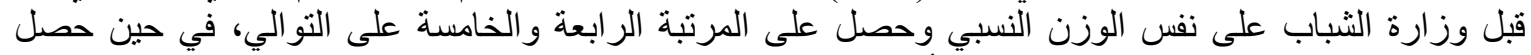

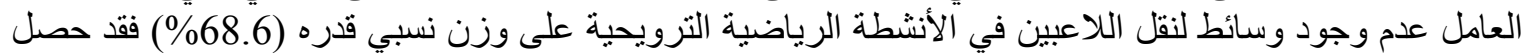

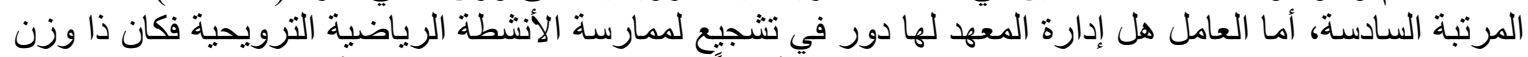

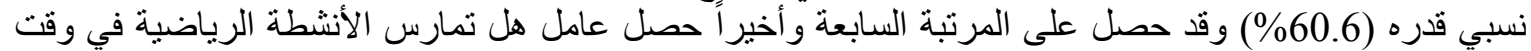

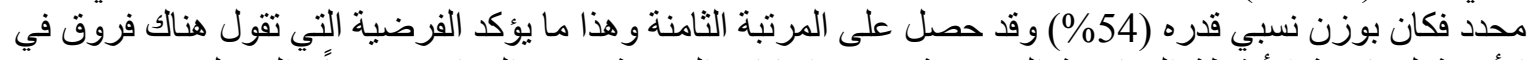

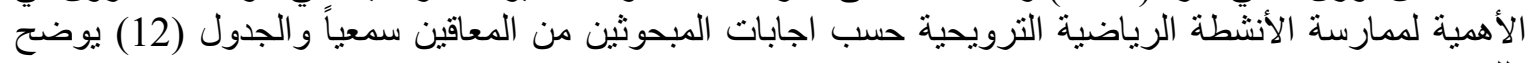

\section{الفصل السادس}

يضم في هذا الفصل محورين المحور الأول أهم النتائج التي توصلت اليها الدراسة، أما الدحور الثاني فتنتاولت

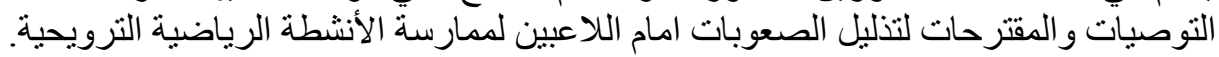

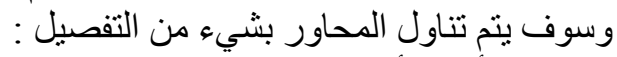
المحور الأول : أهم النتائج التي توصلت التئ اليها البحث وكما يلي :

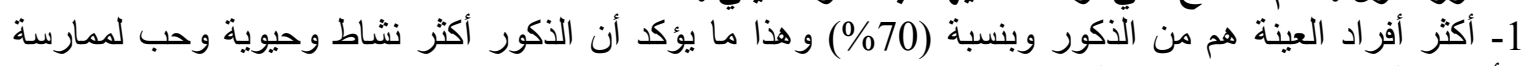

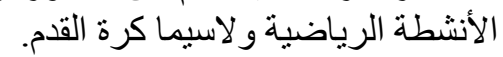

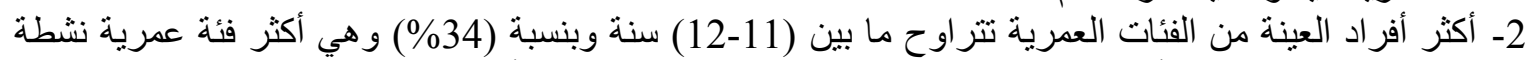

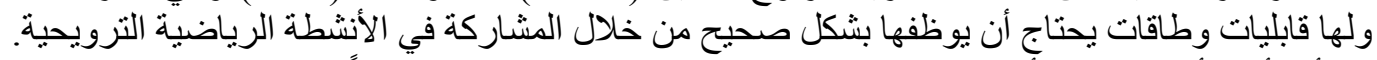

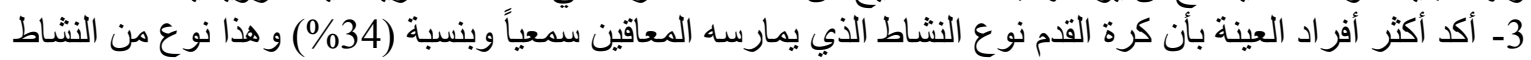

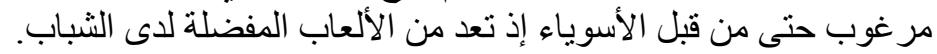

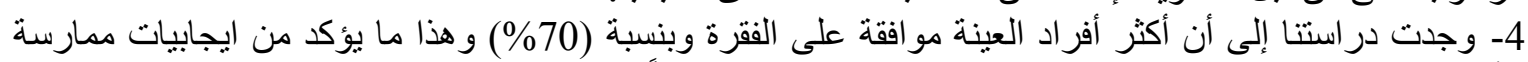

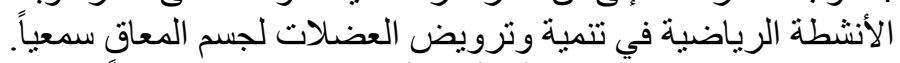

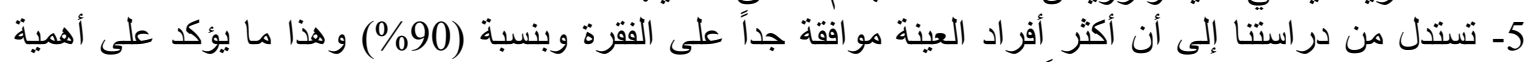

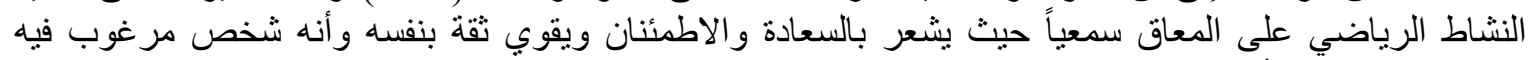
ويندمج مع اقر انه الأسو ياء في المجتمع الذي يعيش في الفيه

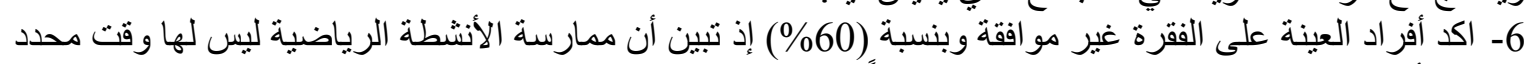

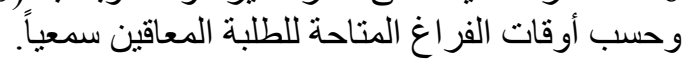

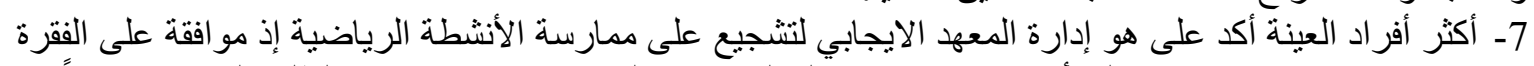

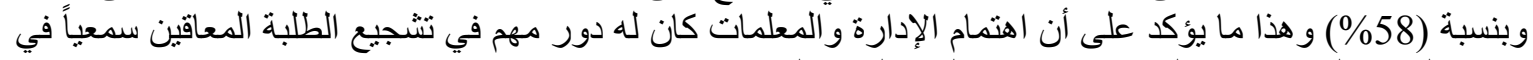

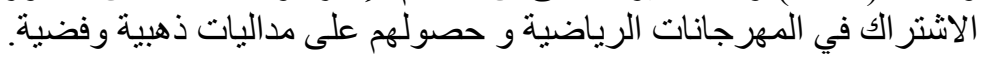

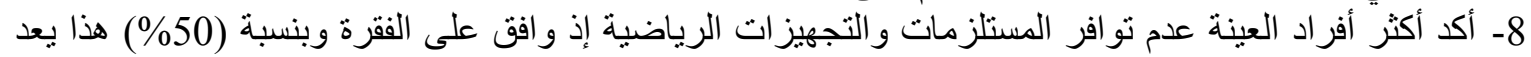

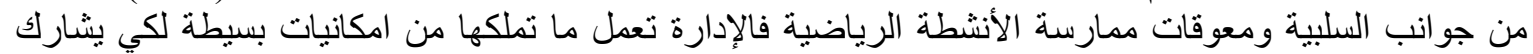
طلبتها المهرجانات والأندية الرياضية واتية.

9- وجدت دراستنا إلى أن أكثر أفر اد العينة يؤكد عدم وجود معلم الفئم مختص بتدريس الطلبة لممارسة الأنشطة الرياضية

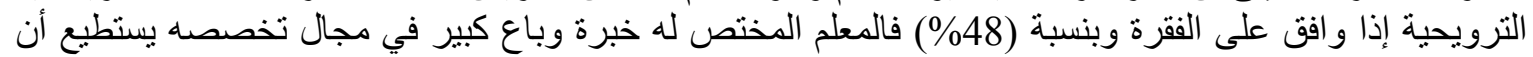

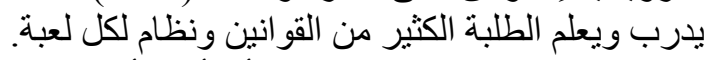

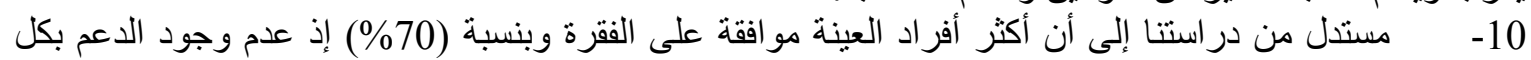

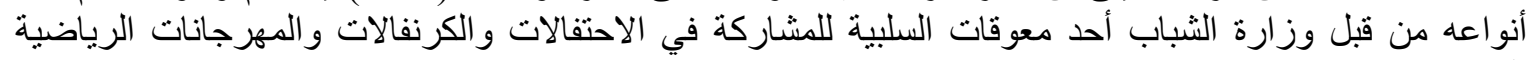




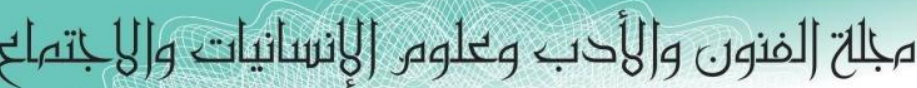

Journal of Arts, Literature, Humanities and Social Sciences

ISSN online: 2414 - 3383

ISSN print: 2616 - 3810

\section{العدد (43) ايلول - سبتهبر 2019}

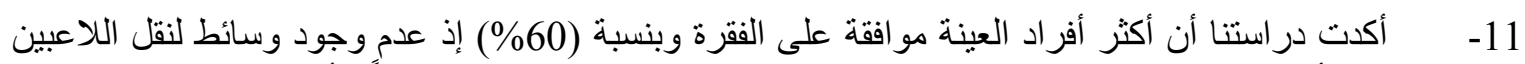

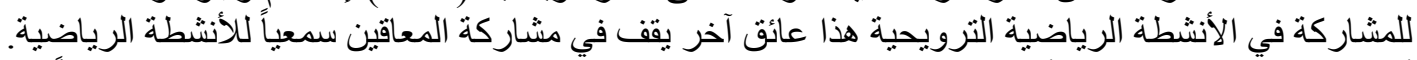

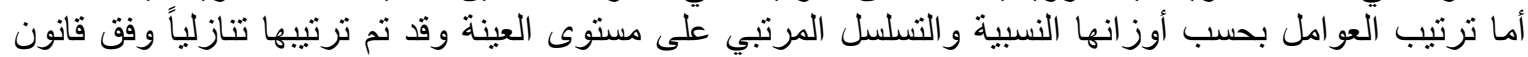
جوزيف كهل، وهي كالآتي:

1- هل ممارسة الأنشطة الرياضية تهدف إلى التنمية الثاملة للفرد المعاق سمعياً نفسياً واجتماعباً وعقلباً (96.6\%).

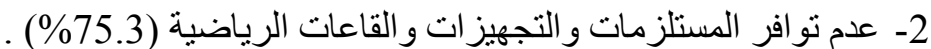

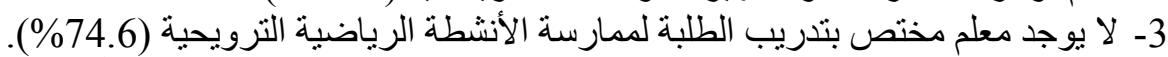

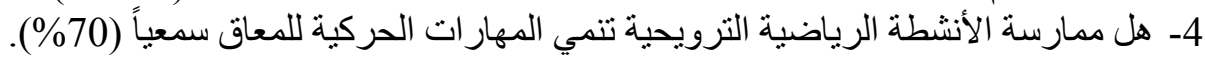

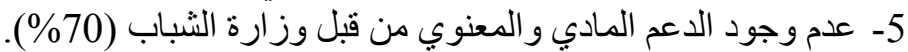

6- عدم وجود وسائط لنقل اللاعبين للمشار كة في الأنشطة الرياضية الترويحية (68\%).

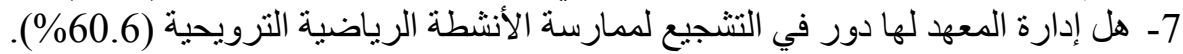

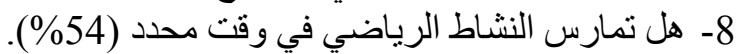

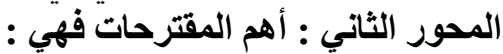

1- على وزارة التربية حث معاهئ معاهد ألمعاقين للمشاركة بالأنشطة الرياضية الترويحية من خلال توزيع وتكريم الفائزين منهم لخلق روح التنافس بينهم.

2- على معاهد المعاقين تكريم الطلبة الفائزين بالمهرجانات لمانيات لها تاثير إيجابي على نفسية المعاق.

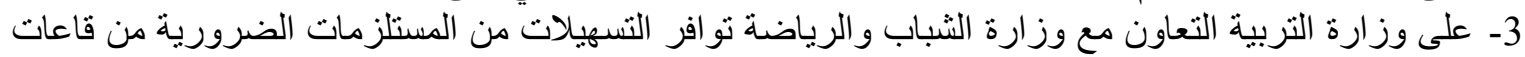

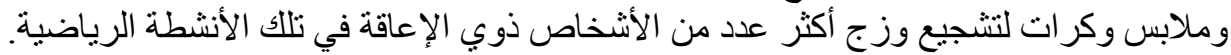

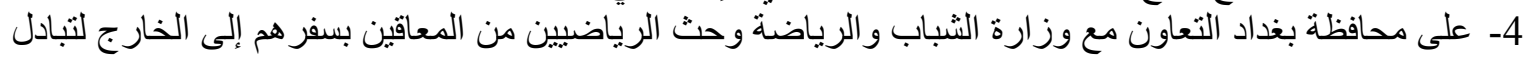

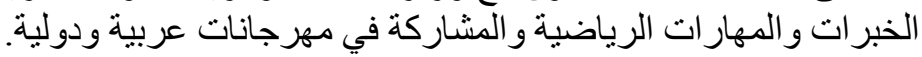

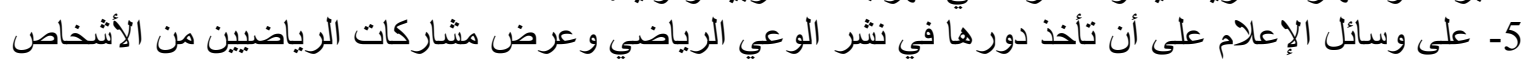
ذوي الإعاقة لما له أثر ايجابي على نفسية المعاق.

\section{References}

1- Dr. Ihsan Mohammed Al-Hassan, Social Research Methods, Jordan, Wael Publishing, $1^{\text {st }}$ edition, 2005 .

2- Dr. Abdulhafiz Sallamah, Designing and Producing Teaching Means for People with Special Needs, Jordan, Al-Yazouri, $1^{\text {st }}$ edition, 2008.

3- Mahmood Al-Hmami \& Ayda Abduleiziy, Recreation between Theory and Application, Cairo, Al-Kitab Center for Publishing, $2^{\text {nd }}$ edition, 1998 .

4- Prof. Assist. Dr. Sahar Adnan Shihab, The Views of Special Education Teachers on The Process of Integrating Disabled in Society, published research in The Journal of Educational and Psychological Sciences, No. 109, 2014.

5- Erikson. (e) adoles cenceet - aquete - didentitc elammarion - paris, 1972.

6- Dr. AbdulSallam Nema Al-Asady, Social Care for Special Needs (Disabled) Baghdad, Board of Technical Education, 2008 .

7- Prof. Assist. Dr. Hassan Hadi Al-Hilaly, Disabled Sport, Baghdad, Al-Faqma Library, 2014 .

8- Taha Saed Ali Abu Al-Lail, Physical Education and Sports for People with Special Needs, Beirut, Al-Fallah Library, $1^{\text {st }}$ edition, 2005.

9- Tonis. Shippen Benrg, Georgef, Koob, "Recent Apvances in Anlmal Models of Drug Addction, Source from the virtual library. 


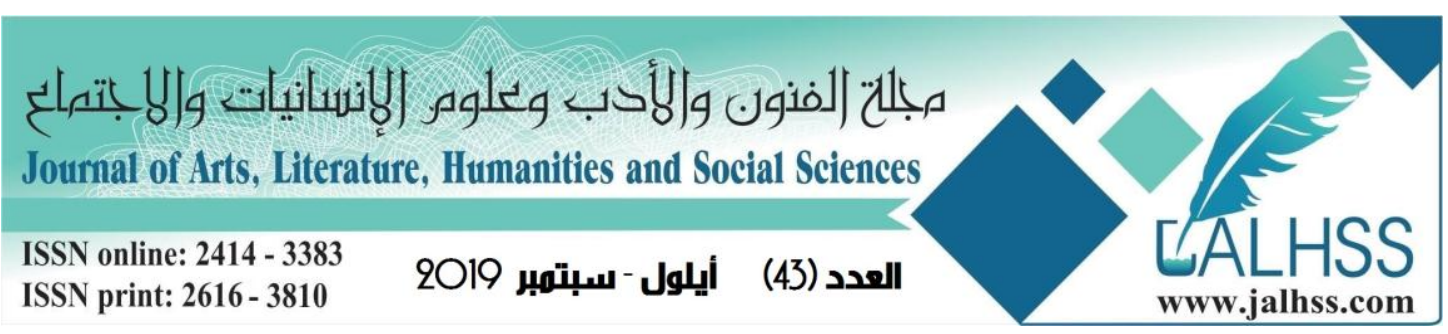

10- Kamal Darweesh, Mahmood Al-Hmami, Vision of Recreation Era of and Leisure, Cairo, Al-Kitab Center for Publishing, $1^{\text {st }}$ edition, 1997.

11- Ammar Humaidat, Impact of Recreational Sports Program at The Social Growth Development for Children with hearing disabilities, a study in the pedagogical center for the deaf and mute in M'sila, Master Thesis, 2016 - 2017.

12- Abdulazeez Sulaiman, The Role of Recreational Sports Activity in achieving social adaptation for Mentally Handicapped Children (Learnable), Master Thesis, Algeria, 2015 $-2016$.

13- Taha Abdulraheem Taha, Introduction to Recreation, Al-Wafaa ldunea for Printing and Publishing, 2006 .

14- Atyat Mohammed Al-Kattab, Leisure and Recreation, Cairo, Al-Ma'arif, $3^{\text {rd }}$ edition, 1982 .

15- Malcom. D.. a maule. Fun damentolofscientivic Method in Psy Chology. W. C. Brown 20 med Duhuque. 1972.

16- Goz Bell Sabirona Alex Zinoviev, Local Urban Sports Clubs and Young Migrant Children in Russia, Journal of Community Development, Vol 51 , No. 4 , 2016 , Source from the virtual library.

17- Hazzam Mohammed Riza Al-Qizuiny, Recreational Education, Baghdad, Arabia for Printing, 1978 .

18- Ameen Anwer Al-Khouly, Physical Education, Al-Fekir Al-Arabi, 2001.

19- Marwan Andulmajeed Ibrahem, Sports for Disabled, Al-Fekir for printing and publishing, $1^{\text {st }}$ edition, 1999 .

20- Thabit Rex and Mergrit Thabit, Localization for Dr. Abed Ali Al-Jesmani Baghdad, Afaq Arabia Library, Al-Fekir Al-Arabi Library, 1984.

21- Robert B. \& Dworth, Psychology, Baghdad, Al-Rasheed Press, 1945.

22- Dr. Essam Hamdi Al-Safadi, Hearing Impairment, Jordan, Al-Yazouri, Arabic Edition, 2007.

23- Dr. Nouri Jafar Ali and Dr. Abdul Razzaq Al-Qaisi, Areas of Special Education, Baghdad, 1991.

24- Jump. Up "skipper. Francis at thames ster new. Zealand" , Papers past. Govt. U. Z. 170 tober. 2011.

25- Jump. Up. "Interntional committce of Sport For the Deaf" Retrieved 12. September 2010.

26- Scott Goodsan, Special Needs Training Translated by Abdul Hakim Jawad Matar, General Secretariat of the Gulf Sports Council.

27- The Spirit of Iraqis Forum of Iraqis and Arabs, in the Al-Amal Department for Special Needs, Iraq, Ministry of Labor and Social Affairs, 2013.

28- Fakher Ali Al-Jamali and et. al., Curriculum for the Hearing Impaired, Iraq, Ministry of Labor and Social Affairs, Department of Educational Supervision and Sports Activity, 2009-2010.

29- Dr. Mohammed Subhi Abu Saleh and et. al., Introduction to Statistical Methods, Jordan, Al Yazouri, 2000. 


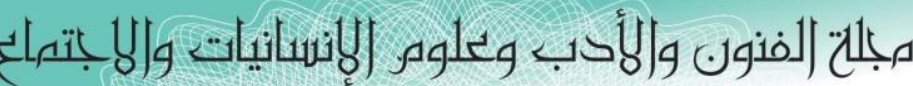

Journal of Arts, Literature, Humanities and Social Sciences

ISSN online: 2414 - 3383

ISSN print: 2616 - 3810

\section{العدد (43) أيلول - سبتمبر 2019}

30- Prof. Dr. Ihsan Mohammed Al-Hassan, Prof. Dr. Abdul Moneim Methods of Social Research, Mosul, 1981.

31- Prof. Dr. Nahida Abdul Karim Hafez, Social Research Methods, Baghdad, 2007.

32- D. Abdulbasset Mohamed Hassan, The Origins of Social Research, Egypt, Wahba Library, $2^{\text {nd }}$ edition, 1977.

33- Ali Abdulrazzaq Al-Chalabi and et. al., Design of Social Research between Strategy and Implementation by Atef Ghaith, Egypt, Al-Mareifa Al-Jamiea, 1983.

34- C. A. Moser, Surrey Ment, hod in Social, investigation Hein - man, London, 1967.

35- Dr. Ali Salim Al-Alawneh, Research Methods in Administrative Sciences,

Fikr, $1^{\text {st }}$ edition, 1996. 
مبلح (لفنون والأدب وعلوه الإنسانيات و ولابتهالع

Journal of Arts, Literature, Humanities and Social Sciences

ISSN online: 2414 - 3383

ISSN print: 2616 - 3810

العدد (43) ايلول - سبتهبر 2019

استمارة الاستبيان

(أهمية النشاط الرياضي الترويحي في دمج الأطفال ذوي الإعاقة السمعية)

(دراسةُ ميدانية في معاهد المعاقين سمعياً)

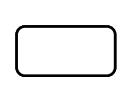

$$
\begin{aligned}
& \text { 1- معلومات عن المبحوث : } \\
& \text { 1- الجنس : ذكر أنتى العي } \\
& \text { 2-1 العمر : } \\
& \text { 3- نو النع النشاط الرياضي الترويحي : }
\end{aligned}
$$

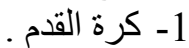

$$
\begin{aligned}
& \text { 2- كرة اليد. } \\
& \text { 3- كرة السلة. } \\
& \text { 4- 3- السباحة. } \\
& \text { 5- الجمناستاك . }
\end{aligned}
$$

4- هل ممارسة الأنشطة الرياضية تنمي المهار اتوات الحركية للمعاق سمعياً : مو افق موافقة جداً غير موافق الافن 5- هل ممارسة الأنشطة الرياضية تهدف إلى التنمية الثاملة للفرد المعاق سمعياً نفسياً واجتماعياً وعقلياً. مو افق موافقة جداً غير موافق الزقي 6- هل تمارس النشاط الرياضي الترويحي في وقت محدد :

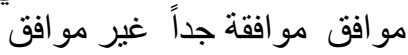

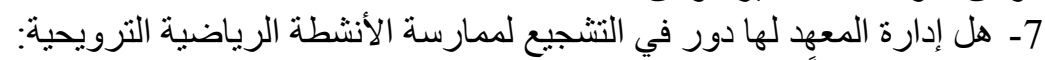

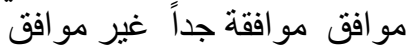
8- عدم تو افر المستلزمات و التجهيزات و والقاعات الرياضية :

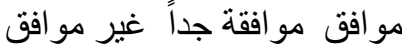

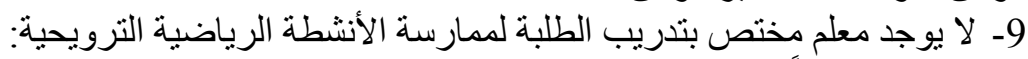
مو افق موافقة جداً غير موافق لاقن 10- عدم وجود الدعم المادي و المعنوي من قبل وزارة الثباب :

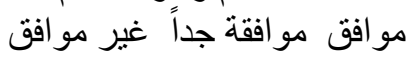

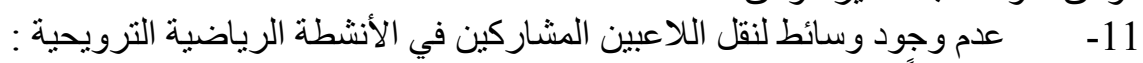
موافق موافقة جداً غير موافق وسائق 